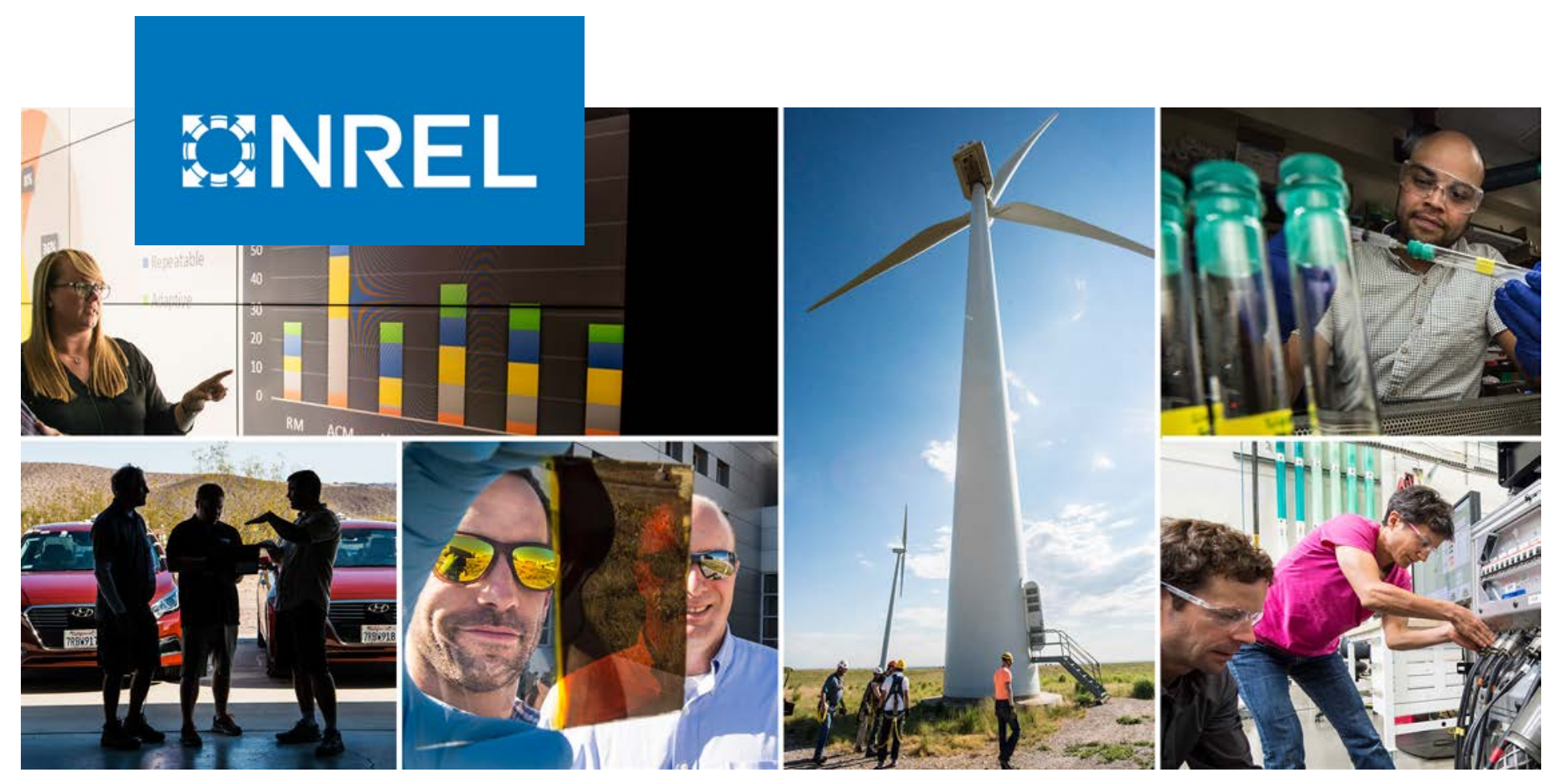

\title{
The Potential for Battery Energy Storage to Provide Peaking Capacity in the United States
}

Paul Denholm, Jacob Nunemaker, Pieter Gagnon, and Wesley Cole

NREL is a national laboratory of the U.S. Department of Energy

Office of Energy Efficiency \& Renewable Energy

Operated by the Alliance for Sustainable Energy, LLC

This report is available at no cost from the National Renewable Energy Laboratory (NREL) at www.nrel.gov/publications.
Technical Report

NREL/TP-6A20-74184

June 2019 


\title{
GNREL
}

\section{The Potential for Battery Energy} Storage to Provide Peaking Capacity in the United States

\author{
Paul Denholm, Jacob Nunemaker, Pieter Gagnon, \\ and Wesley Cole
}

\author{
Suggested Citation \\ Denholm, Paul, Jacob Nunemaker, Pieter Gagnon, and Wesley Cole. 2019. The Potential \\ for Battery Energy Storage to Provide Peaking Capacity in the United States. Golden, CO: \\ National Renewable Energy Laboratory. NREL/TP-6A20-74184. \\ https://www.nrel.gov/docs/fy19osti/74184.pdf.
}

NREL is a national laboratory of the U.S. Department of Energy Office of Energy Efficiency \& Renewable Energy Operated by the Alliance for Sustainable Energy, LLC

This report is available at no cost from the National Renewable Energy Laboratory (NREL) at www.nrel.gov/publications.

Contract No. DE-AC36-08GO28308
Technical Report

NREL/TP-6A20-74184 June 2019

National Renewable Energy Laboratory 15013 Denver West Parkway Golden, CO 80401 303-275-3000 • www.nrel.gov 


\section{NOTICE}

This work was authored by the National Renewable Energy Laboratory, operated by Alliance for Sustainable Energy, LLC, for the U.S. Department of Energy (DOE) under Contract No. DE-AC36-08GO28308. Funding provided by the U.S. Department of Energy Office of Energy Efficiency and Renewable Energy Wind Energy Technologies Office. The views expressed herein do not necessarily represent the views of the DOE or the U.S. Government.

This report is available at no cost from the National Renewable Energy Laboratory (NREL) at www.nrel.gov/publications.

U.S. Department of Energy (DOE) reports produced after 1991 and a growing number of pre-1991 documents are available free via www.OSTI.gov.

Cover Photos by Dennis Schroeder: (clockwise, left to right) NREL 51934, NREL 45897, NREL 42160, NREL 45891, NREL 48097, NREL 46526.

NREL prints on paper that contains recycled content. 


\section{Acknowledgments}

We thank the following individuals for their significant contributions: Aaron Bloom provided valuable feedback on early drafts; Billy Roberts prepared the map; Nick Grue, Michael Rossol and Josh Novacheck helped generate the wind and solar generation profiles; Eduardo Ibanez and Greg Brinkman provided the historical load profiles; and Devonie McCamey provided editing. Valuable feedback was provided by four anonymous reviewers.

This work was authored by the National Renewable Energy Laboratory, operated by Alliance for Sustainable Energy, LLC, for the U.S. Department of Energy (DOE) under Contract No. DEAC36-08GO28308. Funding provided by U.S. Department of Energy Office of Energy Efficiency and Renewable Energy Office of Strategic Programs, Solar Energy Technologies Office, Water Power Technologies Office, and Wind Energy Technologies Office. The views expressed in the article do not necessarily represent the views of the DOE or the U.S. Government. 


\section{List of Acronyms}

AC

BTM

CA

CAISO

CPUC

EIA

ELCC

ERCOT

FRCC

GW

ISO-NE

MISO

MW

NERC

NREL

NSRDB

NWPP

NYISO

PDRC

PV

ReEDS

SERC

SPP

SRSG

VG alternating current

behind-the-meter

California

California Independent System Operator

California Public Utilities Commission

Energy Information Administration

effective load-carrying capability

Electric Reliability Council of Texas

Florida Reliability Coordinating Council

GW

ISO-New England

Midcontinent Independent System Operator

megawatt

North American Electric Reliability Corporation

National Renewable Energy Laboratory

National Solar Resource Database

Northwest Power Pool

New York Independent System Operator

peak demand reduction credit

photovoltaics

Regional Energy Deployment System

Southeastern Electric Reliability Council

Southwest Power Pool

Southwest Reserve Sharing Group

variable generation 


\section{Executive Summary}

Providing peaking capacity could be a significant U.S. market for energy storage. Of particular focus are batteries with 4-hour duration due to rules in several regions along with these batteries' potential to achieve life-cycle cost parity with combustion turbines compared to longer-duration batteries. However, whether 4-hour energy storage can provide peak capacity depends largely on the shape of electricity demand - and under historical grid conditions, beyond about $28 \mathrm{GW}$ nationally, the ability of 4-hour batteries to provide peak capacity begins to fall.

We find that the addition of renewable generation can significantly increase storage's potential by changing the shape of net demand patterns; for example, beyond about $10 \%$ penetration of solar photovoltaics, the national practical potential for 4-hour storage to provide peak capacity doubles. The impact of wind generation is less clear and likely requires more detailed study considering the exchange of wind power across multiple regions. 


\section{Table of Contents}

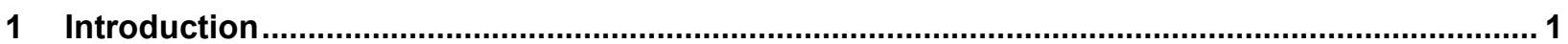

2 The Concept of Peaking Capacity Applied to Energy Storage ................................................. 2

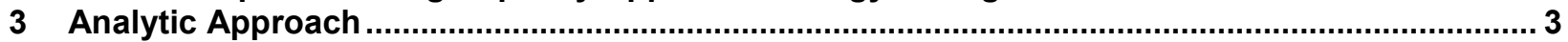

4 Results: Base Cases without the Addition of Wind and Solar ................................................ 7

5 Results: The Potential for Storage to Provide Peaking Capacity Changes with PV and Wind .. 10

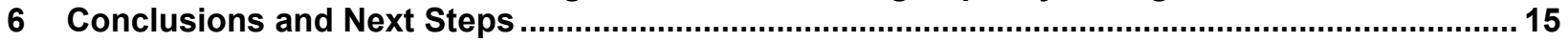

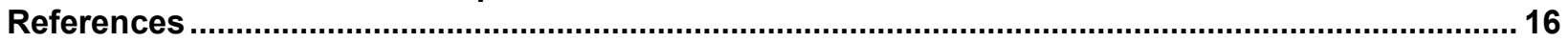

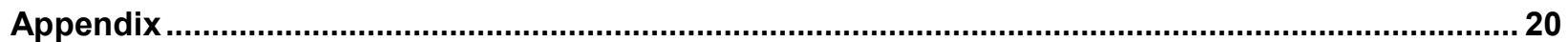

\section{List of Figures}

Figure 1. Map of the regions used in this work. The peak demand reduction of 4-hour energy storage in Florida and New York in 2011 is shown, along with the peak demand reduction credit for both regions as a function of deployed storage capacity....

Figure 2. Base case practical peaking potential for energy storage providing full peak demand reduction credit in 2020.

Figure 3. Practical potential (GW) for 4-hour energy storage with full peak demand reduction as a function of $\mathrm{VG}$ penetration by region in 2020 .

Figure 4. National practical potential (GW) for 4-, 6-, and 8-hour energy storage as a function of VG penetration. 


\section{Introduction}

The deployment of energy storage on the U.S. grid is potentially limited by a variety of factorsprimarily costs, but also performance, material availability (Wadia, Albertus, and Srinivasan 2011), and geographic constraints for technologies such as pumped hydro (Allen 1977). Other limits to grid energy storage deployment include its ability to serve different applications; for example, early market deployments of battery storage for ancillary services such as frequency regulation (DOE 2019) are limited to a few gigawatts (GW), given the inherent size of the market (Denholm, Sun, and Mai 2019).

A key emerging market for stationary storage is the provision of peak capacity, as declining costs for battery storage have led to early deployments to serve peak energy demand (DOE 2019). Much of the storage being installed for peaking capacity has 4 hours of capacity based on regional rules that allow these devices to receive full resource adequacy credit (Maloney 2018). Yet the potential for storage with this or other durations is unclear, which has important implications for policies that support development of energy storage resources.

The potential for limited-duration storage to provide peak capacity is driven in part by its ability to reduce net demand, which is a function of the duration of energy storage and the shape of electricity demand patterns. But as more storage is deployed, the peaking events it serves become longer - so storage must serve a wider part of the demand curve. This reduces the batteries' ability to act as a peaking resource, and therefore decreases their value.

In this study, we explore the potential for utility-scale energy storage to provide peak capacity in the U.S. power grid. We identify the current market for peak capacity generation. We then evaluate the amount of U.S. peak capacity that could be served by storage with different durations, and we examine how this potentially changes with deployment of various combinations of solar photovoltaics (PV) and wind. 


\section{The Concept of Peaking Capacity Applied to Energy Storage}

Peaking capacity represents generators that typically run during periods of high demand, which include simple-cycle gas turbines, gas and oil-fired steam plants, and reciprocating engines (FERC 2015). Pumped hydro storage plants - typically with more than 8 hours of capacity —are also used as peaking capacity (DOE 2019; EPRI 1976). The fleet of conventional generators that provide most U.S. peak capacity today is aging, and future retirements will provide opportunities for substantial amounts of battery storage to enter this market.

Out of the approximately 1,187 GW of U.S. generation capacity (as of the end of 2017), about $261 \mathrm{GW}$ is fossil-fueled peaking capacity (EIA 2018). ${ }^{1}$ Assuming the existing generation fleet has the same retirement characteristics as the historic fleet, we would expect about $150 \mathrm{GW}$ of peak capacity to retire over the next 20 years (Mills, Wiser, and Seel 2017). ${ }^{2}$ The fraction of this capacity that could potentially be replaced with storage of various durations is determined in part by the ability of storage to actually serve peak demand.

The ability of a generator to provide "firm" capacity is defined by its capacity credit, or the fraction of nameplate capacity that contributes to reliably meeting demand (Keane et al. 2011). To achieve a very high capacity credit, a storage device must have sufficient duration (hours of discharge at full capacity) to carry it through the period of peak electricity demand. There have been relatively few estimates of the capacity credit of energy storage using formal methods. Most only examine a fixed amount of storage (PGE 2016; Sioshansi, Madaeni, and Denholm 2014; Johal, Tome, and Collison 2016), and only a few examine the impact of increasing storage deployment on storage capacity credit, which is needed to determine technical or market potential (Alvarez et al. 2017; Hall, Zhang, and Legnard 2018; Shi and Luo 2017).

Overall, the previous literature is not comprehensive in terms of geographical scope, storage penetration level, or the impact of variable-generation wind and solar deployment. Greater assessment is increasingly important as different planning entities are considering or establishing rules for energy storage providing peaking capacity and resource adequacy. As an example, a California Public Utilities Commission (CPUC) rule for California's investor-owned utilities states that storage with 4 hours of continuous discharge capacity is eligible to meet resource adequacy requirements (Chow and Brant 2017; CPUC 2017). The New York Independent System Operator (NYISO) also uses a "4-hour rule" for energy storage to participate in provision of system capacity (NYISO 2017). However, there has been little discussion of how much storage (in megawatts $[\mathrm{MW}]$ of capacity) might be actually capable of meeting peak demand.

\footnotetext{
${ }^{1}$ The total number of internal-combustion, simple-cycle, or steam turbines fired by liquid or gas fossil fuels from the 2017 Energy Information Administration (EIA) Form 860 database, excluding combined heat and power plants, and non-grid-connected generators.

${ }^{2}$ Based on $60 \mathrm{GW}$ of peaking plants that have been shut down since 1980 in EIA Form 860 with average age of 44 years, which also matches the near-term projected average retirement age of peaking plants from Mills et al. 2017.
} 


\section{Analytic Approach}

Traditionally, the ability of a resource to provide reliable capacity is reflected in its capacity credit or effective load-carrying capability (ELCC) (Keane et al. 2011). The standard method of calculating the ELCC of a generator is to add a generator to a base system, and then iteratively add load until the total system reliability (typically measured by loss of load expectation) is the same as the system before the new generator. ELCC approaches rely on a well-defined power system mix, with known capacities and outage probabilities for each generator in each system analyzed, and also considering retirements and additions. Calculating the ELCC of storage depends on either using exogenously determined storage dispatch (e.g., against historic market clearing prices) or integrating storage dispatch into the model. Full ELCC simulations (which are iterative in nature) can be computationally intensive when considering a large number of scenarios, especially when adding an endogenous storage dispatch.

NYISO, the PJM Interconnection, and other regions are actively evaluating storage duration requirements (Maloney 2018), and establishing detailed technically and financially binding rules for energy storage related to resource adequacy will require a rigorous ELCC analysis for each location.

In practice, the results of ELCC calculations typically depend on only a relatively few hours of the year - dominated by a few days of peak demand (Madaeni, Sioshansi, and Denholm 2013). These are hot weekday afternoons for much of the United States, but may also include very cold days, particularly in regions that depend heavily on electric heating. This has led to the adoption of the "capacity factor" approximation approach, which focuses on generator availability during the hours of peak demand (Frew et al. 2017; Denholm and Margolis 2018). For example, previous analysis has demonstrated that under historical conditions, examination of solar and wind output during the highest net load hours of the year would provide an accurate assessment of capacity credit (Madaeni, Sioshansi, and Denholm 2013).

To estimate a regional and national potential for energy storage under a large range of variable generation (VG) penetrations, storage capacity, and durations, we use an approximation technique similar to the capacity factor approximation. Our approach determines how much storage (both power and energy) is needed to reduce net peak demand. This is also similar to evaluating energy storage's contribution to the planning reserve margin, which is typically assessed at the annual peak demand period (NERC 2018). As such, we refer to this approximation as the "peak demand reduction credit" (PDRC). Our analysis is performed for 18 U.S. regions that are based on the North American Electric Reliability Corporation (NERC) "Assessment Areas" shown in Figure 1 (NERC 2018). Because of the size of Midcontinent Independent System Operator (MISO) and PJM, these were divided into smaller regions [west and east] to evaluate the impact of different demand patterns. We also divided the Northwest Power Pool (NWPP) into two regions to capture the impact of winter-peaking loads in the Pacific Northwest.

The model first determines a net peak demand target, equal to the annual peak demand minus storage power capacity. The storage power capacity is initially set to $0.1 \%$ of annual peak demand, and incrementally increased by steps equal to this capacity, up to a $30 \%$ reduction in annual peak demand. For each net peak demand target, the model steps through the hourly load 
data (net of wind and solar), discharging storage if load is greater than a net peak demand target. The battery charges if the load is less than the peak demand target (while ensuring that the charging does not result in peak net demand that exceeds the target value). The charge/discharge energy is tracked as a cumulative variable, including an $80 \%$ roundtrip (AC) efficiency. After stepping through a full year of data, the maximum value of the cumulative variable (assuming discharge energy is positive) is identified. That is the amount of energy capacity required to achieve the desired peak reduction for the given net load profile, assuming perfect foresight and no forced outages of the storage unit. Imperfect forecasts could require a small amount of additional storage energy capacity to mitigate errors in the timing of discharge. This amount should be relatively small based on trends in forecasting of load and solar (Salles et al. 2017; Zhang et al. 2019).

Figure 1 shows the regions evaluated, an example of our method, and results for two regions: the Florida Reliability Coordinating Council (FRCC) and NYISO. The hourly load profiles (lower right) show the day of highest load for each region in 2011 including the impact of simulated storage. The profiles show the point at which 4-hour storage can no longer reduce the net peak demand by the power capacity of the storage plant (meaning the PDRC of 4-hour storage has fallen below 100\%). 


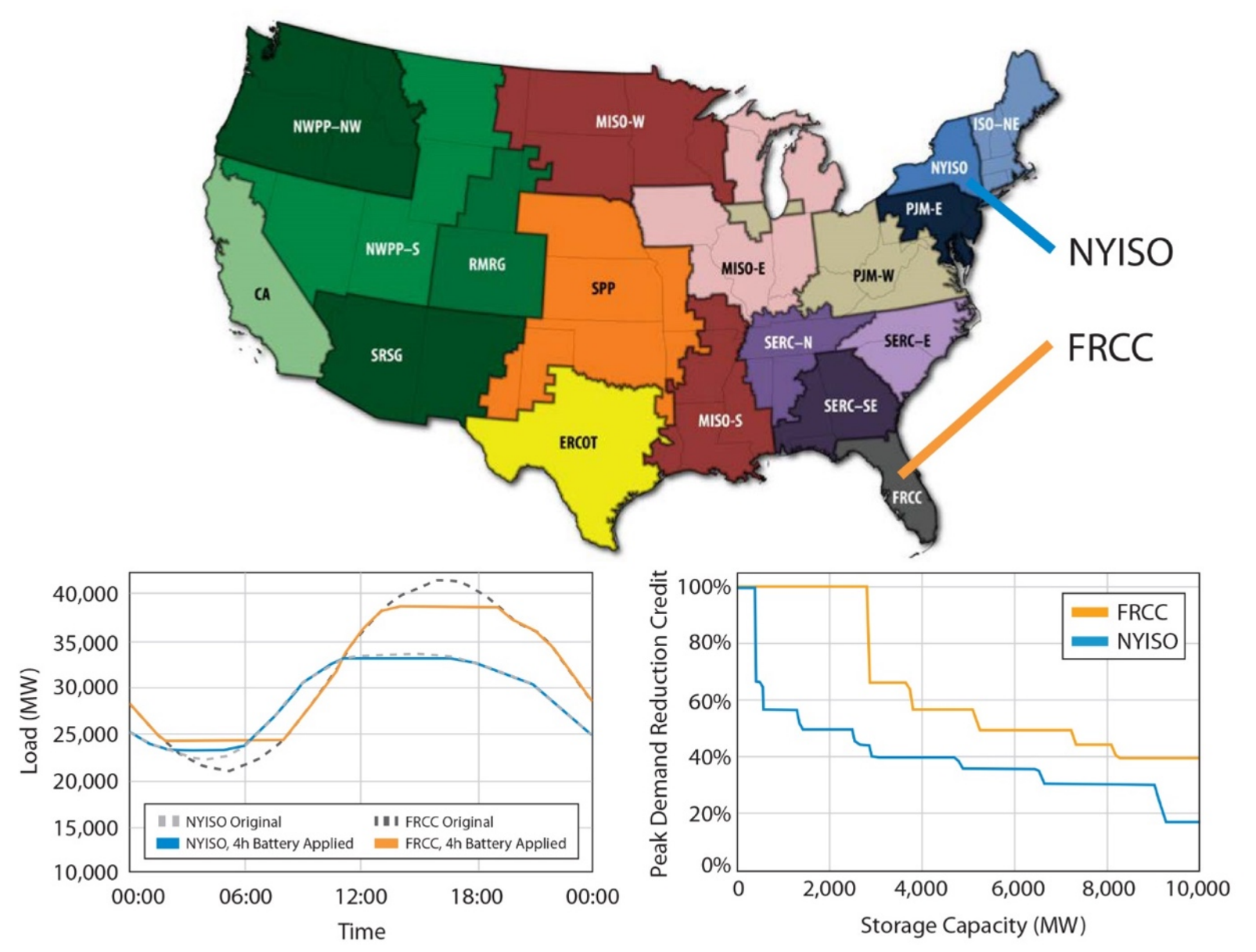

Figure 1. Map of the regions used in this work. The peak demand reduction of 4-hour energy storage in Florida and New York in 2011 is shown, along with the peak demand reduction credit for both regions as a function of deployed storage capacity.

In Florida about 2,850 MW of 4-hour storage can be deployed with a PDRC of 100\% using 2011 data. Assuming perfect foresight of electricity demand, this suggests that 4-hour storage could effectively contribute $2,850 \mathrm{MW}$ of capacity toward the system planning reserve margin. In NYISO, only about $440 \mathrm{MW}$ of 4-hour storage can be deployed with full PDRC, despite NYSIO having a peak that is only about $20 \%$ lower in this year. The reason can be seen in the left subplot of Figure 1: the width of the peak demand in NYISO is much wider than that of FRCC.

These threshold values do not mean that the 4-hour storage device can no longer provide any usable system capacity; rather, they mean that each MW of storage power capacity can no longer reduce the peak demand by $1 \mathrm{MW}$, implying a declining PDRC. The right curve in Figure 1 illustrates the PDRC for both locations as a function of penetration for a 4-hour storage device.

At the threshold value where the PDRC of 4-hour storage falls below 100\%, the width of the net load peak actually exceeds 4 hours; this is because the entire peak event does not require the full power of the storage capacity, so energy can be rationed out during the shoulder hours to have the device ride through a longer peak. In the Florida example, this point is reached at 2,850 MW 
of storage, where the peak demand period has widened to 6 hours. This creates a discontinuity in the PRDC for any additional 4-hour storage beyond that point. To reduce the peak demand further, any additional 4-hour storage must discharge at less than full rating for 6 hours, which produces an effective PDRC of $4 / 6$ or about $67 \%$. Further 4-hour storage beyond that would earn steadily less PRDC, as peaks get wider and peak days shift. The NYISO case shows an even more rapid drop to the point where the incremental PDRC falls below $50 \%$ after total installations of about 2,570 MW. Discontinuities in the data result from using discrete hourly load patterns. Using subhourly time intervals would smooth the curves, but the general shape would stay the same.

The declining ability of 4-hour energy storage to reduce peak demand would require utilities or developers to de-rate 4-hour storage at the "threshold" value where the PDRC falls below 100\% (potentially reducing capacity payments or other revenue associated with resource adequacy). This substantially decreases the economic value of 4-hour storage - and the rapid decline in its PDRC implies a "practical" limit to its use as peaking capacity. As a result, continued economic use of storage as peaking capacity might require deployment of longer-duration storage. This could produce a trajectory in which 4-hour storage is built first, until it reaches the point of diminishing capacity value at some point in the future, allowing developers to take advantage of declining battery prices (Kittner, Lill, and Kammen 2017; Schmidt et al. 2019) and then build longer-duration storage. 


\section{Results: Base Cases without the Addition of Wind and Solar}

At each location we construct a "practical peaking potential" for energy storage of different durations using 7 years of data. Hourly load data for 2007-2013 was obtained from the Federal Energy Regulatory Commission's Form 714 database (FERC 2018) and ISO websites. ${ }^{3}$ At each location, we add 4-hour storage until the point at which the PDRC drops below $100 \%$, establishing the threshold value for practical potential for storage of this duration. We then build 6-hour storage and subsequently 8-hour storage, finding the point at which the PDRC falls below 1 for each.

Once the threshold value is determined (MW of storage capacity), we normalize this value by dividing this value by the peak demand in that year. For the base case (no wind or solar), across the 7 years of data, we selected the year that shows the lowest normalized threshold value, with the exception of one region. In all summer-peaking systems, the relationship between normalized threshold value and annual peak demand data shows either no relationship or a small negative correlation, indicating that storage does slightly worse in the years with highest demand, which would typically be the basis for the system planning reserve margin. In the NWPP-NW (a winter peaking region), storage actually performs better as a function of peak demand, so we chose an "average" year (2013) for that region. For the cases with added wind and solar in NWPP-NW we used the lowest value, as there is no clear trend, so we revert to the most conservative approach.

The lowest value of the seven years of data is then multiplied by the anticipated peak demand in 2020. This value is the practical potential for energy storage of a given duration. The 2020 peak demand in each region is derived from the NERC 2018 Long-Term Reliability Assessment.

Figure 2 shows the results for each region. Figure 2 a measures the storage capacity relative to annual peak demand (i.e., the practical peaking potential in MW divided by the annual peak demand). This normalizes the results for the purposes of comparison among regions. The figure also shows which year was chosen, using the lowest value of the 7 years analyzed for all regions except for NWPP-NW, which uses 2013. Normalizing to annual peak also allows us to scale the storage to different annual peak demands for the purpose of evaluating the potential of storage in future years. Figure $2 \mathrm{~b}$ provides a total regional and national practical potential for incremental 4-, 6-, and 8-hour capacity storage providing full PDRC in 2020. This represents our base case practical peaking potential, assuming no deployment of wind or solar.

\footnotetext{
${ }^{3}$ Because the boundaries of several regions in the Eastern Interconnection changed between 2007 and 2013 (mainly MISO, Southwest Power Pool [SPP], and Southeastern Electric Reliability Council [SERC]), some loads in older years were shifted to correspond to current boundaries. Because the System Advisor Model (the tool used to generate PV data) does not allow for years with more than 365 days, the last day of the year (12/31) was removed from the 2008 and 2012 load data, and those days were spot checked to ensure they would not impact the results.
} 


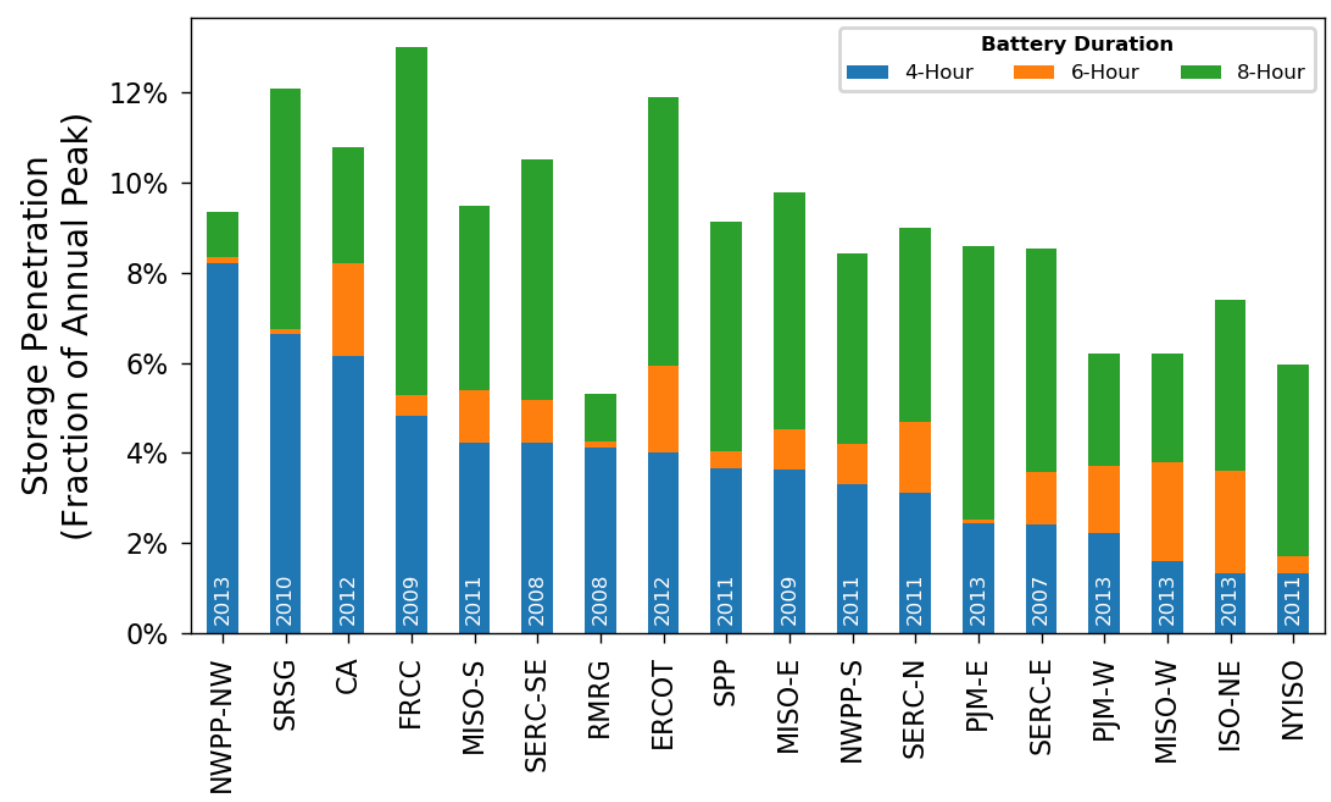

a) Measured relative to peak demand

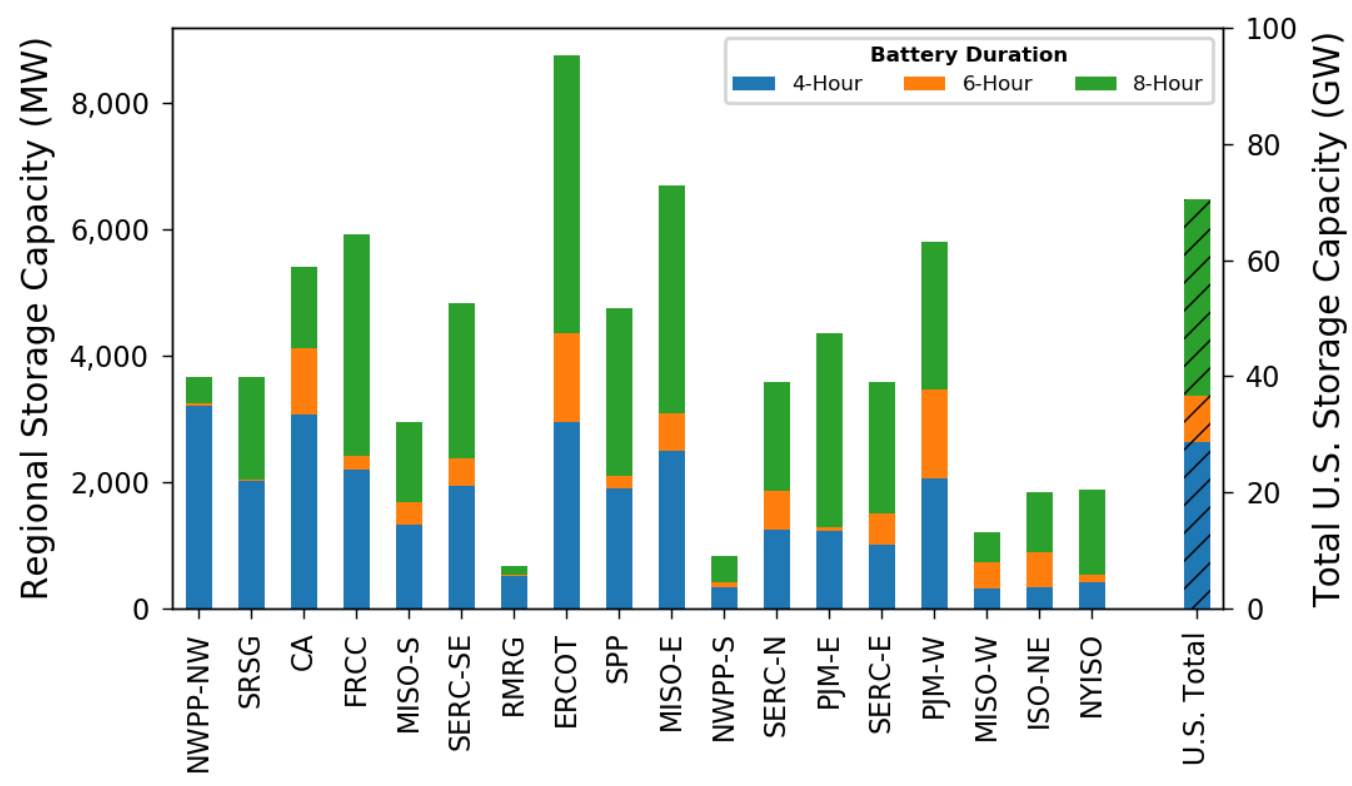

b) Measured by capacity (based on 2020 peak demand)

Figure 2. Base case practical peaking potential for energy storage providing full peak demand reduction credit in 2020 .

Figure 2a demonstrates the much greater ability of 4-hour storage to reduce peak demand in strongly summer-peaking systems such as in California and the Southwest Reserve Sharing Group (SRSG) compared to regions that, while still summer peaking, have longer-duration peaks. The NWPP-NW also shows a relatively large potential for 4-hour storage based on the shape of the winter peaks. The practical potential for 4-hour storage at full PDRC is about 28 
GW. This about four times greater than the entire regulating reserve requirement in the United States (Denholm, Sun, and Mai 2019).

The step from 4 hours to 6 hours is relatively small (about $8 \mathrm{GW}$ ), because the first 4 hours of storage typically widens the peak to about 6 hours, leaving little room for 6 -hour storage. The 8 hour step is much larger (about $34 \mathrm{GW}$ ), leading to a total potential for combined durations of about $70 \mathrm{GW}$. This is much lower than the total installed peaking capacity $(261 \mathrm{GW})$ and less than half of the expected 20 -year retirement number of $150 \mathrm{GW}$. However, these values do not account for the large increase in potential that results from the impact of renewable energy on net load shapes. 


\section{Results: The Potential for Storage to Provide Peaking Capacity Changes with PV and Wind}

A number of analyses have demonstrated that PV can change the net load shape and potentially increase energy storage's capacity credit or reduce the storage duration needed for full capacity credit (Perez et al 2008; Jorgenson, Denholm, and Mehos 2014; Strategen Consulting 2017). Fewer analyses have looked at the effect of wind or the combination of wind and solar.

To quantify the impact of wind and solar on the practical potential of storage to provide peaking capacity, we repeat our simulations for all data sets with the addition of PV (up to $35 \%$ on an annual basis for all regions) and wind (also up to 35\% depending on the resource availability).

Wind and solar sites were selected using the Regional Energy Deployment System (ReEDS) capacity expansion model. ReEDS is a national-scale model that minimizes the total system cost as it selects generation and transmission technologies to meet system requirements (Eurek et al. 2016). The specified penetration levels were implemented in ReEDS as model constraints at the state level, such that each state had to meet the required annual penetration of wind and PV. This requirement can be met from in-state generators or from bundled trading of wind and PV from nearby states. Because of our focus on peaking capacity, only resources within the NERC assessment area were considered to contribute to capacity requirements. For regions with insufficient wind resources (FRCC, ISO-New England [ISO-NE], CA, and SERC), generation profiles for surrounding regions were used.

For PV, we assumed an approximately equal mix (on an energy basis) of fixed installations and single-axis tracking installations. Once the quantities of wind and PV were established in each of the 356 ReEDS regions, hourly generation profiles for 2007-2013 were generated using the reV model (Maclaurin et al. forthcoming) with resource data from the National Solar Resource Database (NSRDB) (Sengupta et al. 2015) and the WIND Toolkit (Draxl et al. 2015).

Existing wind and utility-scale solar were not considered for the zero-renewables cases. Some behind-the-meter (BTM) PV existed in the later years and is represented within the load data. This means that the zero PV cases actually have a small amount of BTM PV in some locations. Because most of the BTM PV has been installed in the last few years (after 2013), the overall impact should be relatively small. In our cases with renewables, the cases first used simulated profiles from existing locations and capacities, and then added new locations as selected by ReEDS. We used simulated weather data (rather than measured wind and PV generator profiles) for all cases for consistency; this is because relatively few wind and solar projects were installed before 2007, and we did not have access to 7 years of actual measured generator output from most of those projects.

Figure 3 provides results for five regions that show some of the relationships we observed between VG deployment and the ability of 4-hour storage to reduce peak demand. The results for all 18 regions are provided in the Appendix. The amount of 4-hour storage capacity with full PDRC is shown as a function of PV penetration, while the various wind penetrations are shown as different points at each PV penetration level. As before, our study uses the most conservative (i.e., lowest) value for all summer-peaking regions, including for NWPP-NW, which is winter peaking. The NYISO case (also seen in FRCC and ISO-NE) shows a fairly strong relationship 
between PV penetration and storage capacity with full PDRC, with modest impact of wind. The SRSG case (also seen in the CA curve) is similar in shape to the NYISO curve, but shows a drop in PDRC with penetrations of $\mathrm{PV}$ in the range of $5 \%-10 \%$. This drop results from PV clipping the peak and widening the net load pattern, but it only occurs at relatively low penetration until the net load peak is shifted to later in the afternoon (Denholm and Margolis 2018). All other cases except NWPP-NW show increase in PDRC as a function of PV penetration, but with greater variability as a function of wind, or with discontinuities. Some locations also show a drop in PDRC at low PV penetration, similar to the SRSG case. In addition, the benefits of PV in some regions saturate, sometimes due to a seasonal shift in net peak demand from summer to winter. In locations where there is significant variability in PDRC as a function of wind, there are few consistent patterns across all regions. The MISO-E region shows most points above the zerowind case, where wind acts to further narrow the peak, thereby increasing PDRC. However, there are other cases, such as SPP, where adding wind tends to decrease PDRC. In these cases, wind is flattening load and providing capacity credit, similar to the impact of PV at low penetration. Finally, the NWPP-NW case shows a very limited benefit from PV, due to the winter peak and limited solar output on this day, and it is the only case we found in which wind can negate the impact of PV on changing the net load shape and enabling greater amounts of 4hour storage. 

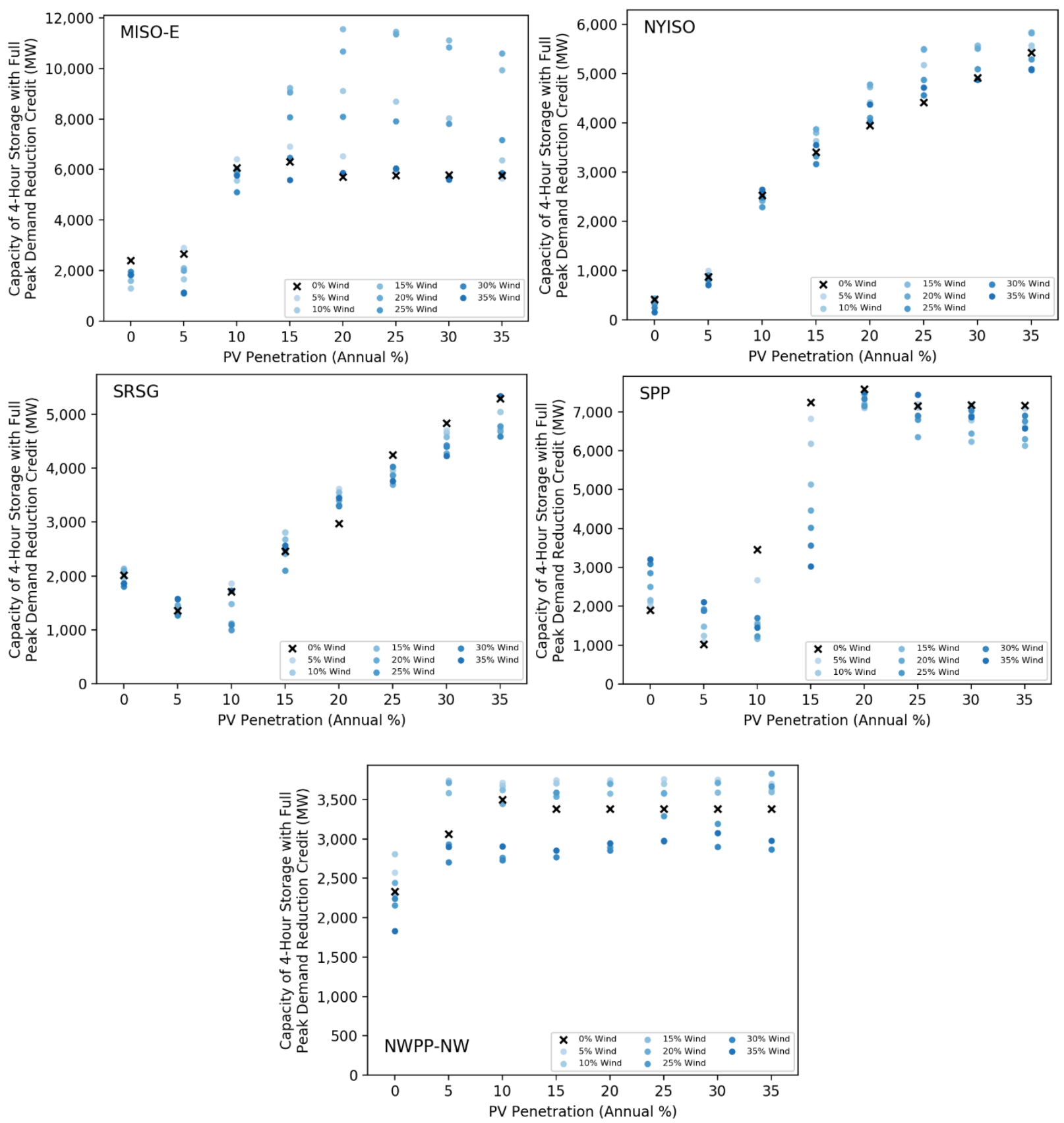

Figure 3. Practical potential (GW) for 4-hour energy storage with full peak demand reduction as a function of VG penetration by region in 2020.

The results in Figure 3 show that significant changes in net load and corresponding impact on storage potential can occur at relatively low penetrations of PV (5\%-10\%), implying a near-term impact for regions with aggressive PV deployment goals. Some regions such as California have already deployed sufficient PV to demonstrate increased potential for 4-hour storage. For example, California is projected to exceed 15\% PV penetration by 2020 (Denholm and Margolis 2018), implying a greater than 1,000 MW increase in potential for 4-hour storage compared to the zero-solar case. Early storage deployments could be a key element to further reducing 
costs - and point to the continued need to assess the actual regional duration requirements in an evolving grid.

Translating these results into a national practical potential requires choosing scenarios for PV and wind penetration at each location. These technologies are not currently deployed uniformly across the United States, so we sampled various combinations of wind and solar at each location, aggregated to the national level.

Figure 4 shows the overall national practical potential for energy storage for about 20,000 combinations of VG penetration. ${ }^{4}$ The $\mathrm{x}$-axis provides the total amount of PV deployed nationally, and thus represents many combinations of PV deployment in each region. The lower bound of 2.3\% represents the amount of PV deployed in 2018, with simulated PV deployed in historical locations (EIA 2019). At each PV penetration, we also evaluate a large number of wind penetrations. The $y$-axes represent the national practical potential for storage with full PDRC assuming 2020 peak demand projections (when deployed sequentially from 4 to 6 to 8 hours). The curves show both a mean trendline and a band that captures $90 \%$ of the scenarios evaluated. The data shown intends to capture only the general relationship between variable generation deployment and storage potential, as the results include unlikely scenarios (e.g., concentrations of PV and wind in locations with poor resource, or cases in which wind-rich regions deploy mostly solar). Following regional results, there is a strong positive relationship between national practical potential for storage and PV deployment. Overall, the practical potential for 4-hour storage appears to nearly double by the time PV achieves about a $10 \%$ national average penetration (compared to the 2018 PV case).

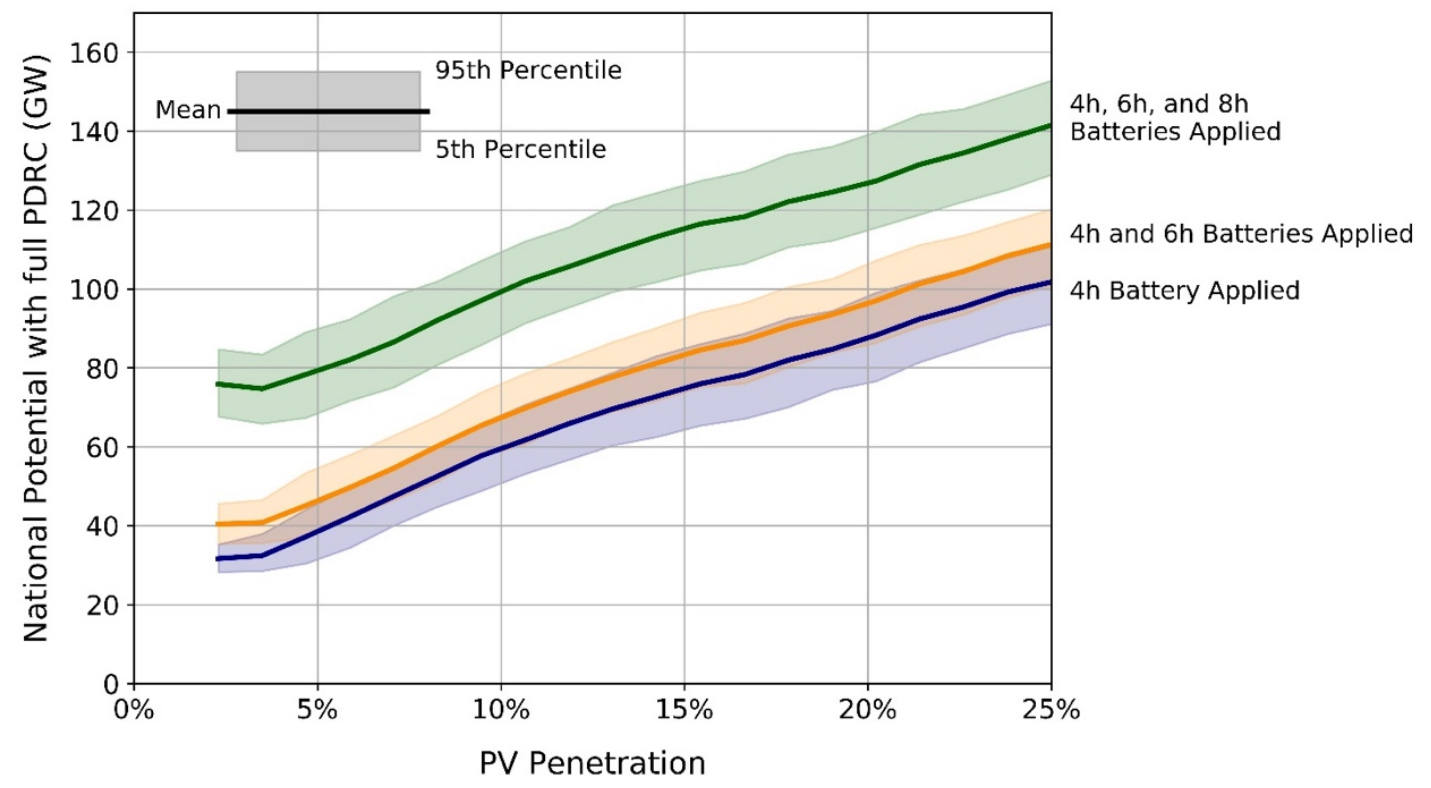

Figure 4. National practical potential (GW) for 4-, 6-, and 8-hour energy storage as a function of VG penetration.

${ }^{4}$ Data are grouped into 20 equally spaced PV penetration bins for mean and percentile calculations, and lines were drawn from the center point of each bin. 
Curves showing the relationships between wind penetration and storage potential are provided in the Appendix and demonstrate no observable trends. This implies that solar would be the main driver behind any change in the ability of storage to meet peak demand. 


\section{Conclusions and Next Steps}

We demonstrate the opportunity for utility-scale battery storage to satisfy a substantial portion of U.S. peak capacity needs and thus expand beyond its current role in the relatively small ancillary services market. This analysis demonstrates roughly $28 \mathrm{GW}$ of practical potential for 4-hour storage providing peaking capacity, assuming current grid conditions and demand patterns. This deployment could help decrease storage costs - and storage deployed primarily to provide peaking capacity can provide additional benefits, such as a sink for low- or zero-value PV generation during non-peak periods. This in turn can enable greater PV deployment, which then increases the potential of 4-hour storage. This effect can extend the practical potential for 4-hour storage to $50 \mathrm{GW}$ or beyond nationally (assuming PV provides $10 \%$ of the nation's electricity demand). Of course, there could be significant regional impacts, as the areas first to adopt 4-hour storage could saturate their potential before full national deployment is reached. However, the general effect should provide additional potential for cost reductions to increase the competitiveness of 6- or 8-hour storage.

The results show significant potential for energy storage to replace peaking capacity, and that this potential grows as a function of PV deployment. Our analysis (particularly Figure 3) focuses on 4-hour storage due both to current policy drivers (CPUC 2017) and the near-term cost competitiveness of 4-hour batteries compared to those with longer duration. A key performance metric is the "breakeven" cost of batteries required to achieve life-cycle cost parity compared to traditional peaking resources. This breakeven cost is not a simple equivalence of capital costs due to a variety of factors, including the shorter lifetime of batteries and the greater operational flexibility of batteries compared to combustion turbines. The relative value of storage providing system flexibility (i.e., time-shifting of generation resources and avoided thermal plant starts) increases the value of batteries relative to combustion turbines and will vary by grid mix, fuel price, and storage size. Additional analysis is required to evaluate this breakeven cost as a function of deployment, considering the change in value as a function of PV deployment (which generally increases the value of storage) and the value of storage deployment (which decreases the value of storage). This will vary regionally as a function of these parameters plus the mix of other generation resources.

This preliminary analysis does not consider several elements that could affect the potential of storage to provide peaking capacity. Because this work relies on historical load patterns, it does not consider the possible impacts of changing electricity load patterns due to demographic shifts, climate (Auffhammer, Baylis, and Hausman 2017), and electric vehicles (Mai et al. 2018) in the decadal time scales needed to achieve greatly increased PV penetration (NREL 2018). It also does not consider how additional transmission could enable larger regional sharing of wind and solar resources that could impact net profiles. Finally, while these results provide a basic indication of the overall potential for storage to provide peaking capacity, robust regional calculations using standardized effective load-carrying capability calculations will be needed to verify the results for any specific location. 


\section{References}

Allen, A. E. (1977). "Potential for Conventional and Underground Pumped-Storage."

IEEE Transactions on Power Apparatus and Systems PAS-96(3):993-998.

Alvarez, Antonio, Will Dong, Ben Moradzadeh, Carl Nolen, Rob Anderson, Thomas Edmunds, John Grosh et al. (2017). Role of Operating Flexibility in Planning Studies. CPUC/California Energy System for the $21^{\text {st }}$ Century.

http://docs.cpuc.ca.gov/PublishedDocs/Efile/G000/M195/K586/195586923.PDF.

Auffhammer, Maximilian, Patrick Baylis, and Catherine H. Hausman. (2017). "Climate Change is Projected to Have Severe Impacts on the Frequency and Intensity of Peak Electricity Demand Across the United States.” PNAS 114(8): 1886-1891. https://doi.org/10.1073/pnas.1613193114.

Chow, Lliy, and Simone Brant. (2017). The 2016 Resource Adequacy Report. San Francisco, CA: California Public Utilities Commission.

http://www.cpuc.ca.gov/WorkArea/DownloadAsset.aspx?id=6442453942

CPUC (California Public Utilities Commission). (2017). "Resource Adequacy." Accessed December 2017: http://www.cpuc.ca.gov/RA/.

Denholm, Paul, and Robert Margolis. (2018). The Potential for Energy Storage to Provide Peaking Capacity in California Under Increased Penetration of Solar Photovoltaics. Golden, CO: National Renewable Energy Laboratory. NREL/TP-6A20-70905.

https://doi.org/10.2172/1427348.

Denholm, Paul, Yinong Sun, and Trieu Mai. (2019). An Introduction to Grid Services: Concepts, Technical Requirements, and Provision from Wind. Golden, CO: National Renewable Energy Laboratory. NREL/TP-6A20-72578. https://doi.org/10.2172/1505934.

DOE (U.S. Department of Energy). (2019). “DOE Global Energy Storage Database.” http://www.energystorageexchange.org/.

Draxl, Caroline, Andrew Clifton, Bri-Mathias Hodge, and Jim McCaa. (2015). "The Wind Integration National Dataset (WIND) Toolkit.” Applied Energy 151: 355-366. https://doi.org/10.1016/j.apenergy.2015.03.121.

EPRI (Electric Power Research Institute). (1976). Assessment of Energy Storage Systems Suitable for Use by Electric Utilities. Palo Alto, CA: Electric Power Research Institute. EPRIEM-264.

EIA (Energy Information Administration). (2019). Electric Power Monthly with Data for December 2018. February 2019.

https://www.eia.gov/electricity/monthly/current_month/epm.pdf.

—. (2018). "Form EIA-860 Detailed Data." https://www.eia.gov/electricity/data/eia860/. 
Eurek, Kelly, Wesley Cole, David Bielen, Nate Blair, Stuart Cohen, Bethany Frew, Jonathan Ho, et al. (2016). Regional Energy Deployment System (ReEDS) Model Documentation: Version 2016. Golden, CO: National Renewable Energy Laboratory. NREL/TP-6A20-67067.

https://doi.org/10.2172/1332909.

FERC (Federal Energy Regulatory Commission). (2018). "Form 714: Annual Electric Balancing Authority Area and Planning Area Report.” http://www.ferc.gov/docs-filing/forms/form714/data.asp.

- (2015). Energy Primer: A Handbook of Energy Market Basics. https://www.ferc.gov/market-oversight/guide/energy-primer.pdf

Frew, Bethany, Wesley Cole, Yinong Sun, James Richards, and Trieu Mai. 2017. 8760-Based Method for Representing Variable Generation Capacity Value in Capacity Expansion Models. Golden, CO: National Renewable Energy Laboratory. NREL/CP-6A20-68869.

Hall, Wes, Bei Zhang, and Thomas Legnard. (2018). Valuing Capacity for Resources with Energy Limitations. GE Energy Consulting. https://www.nyiso.com/documents/20142/2547799/Capacity\%20Value\%20of\%20Resources\%20 with\%20Energy\%20Limitations.pdf/27519226-afb5-a440-fcac-669e38a8c2ec.

Johal, Harjeet, Douglas Feitosa Tome, and Kenneth Collison. (2016). Unlocking the Hidden (Capacity) Value in Energy Storage. Fairfax, VA: ICF.

Jorgenson, J., P. Denholm, M. and Mehos. (2014). Estimating the Value of Utility-Scale Solar Technologies in California under a 40\% Renewable Portfolio Standard. Golden, CO: National Renewable Energy Laboratory. NREL/TP-6A20-61685. https://doi.org/10.2172/1134134.

Keane, Andrew, Michael Milligan, Chris J. Dent, Bernhard Hasche, Claudine D’Annunzio, Ken Dragoon, and Mark O'Malley. (2011). "Capacity Value of Wind Power." IEEE Transactions on Power Systems 26(2): 564-572.

Kittner, Noah, Felix Lill, and Daniel M. Kammen. (2017). "Energy Storage Deployment and Innovation for the Clean Energy Transition." Nature 2, 17125.

http://dx.doi.org/10.1038/nenergy.2017.125.

Maclaurin, Galen et al. (forthcoming). The Renewable Energy Potential (reV) Model: A Geospatial Platform for Technical Potential and Supply Curve Modeling. Golden, CO: National Renewable Energy Laboratory. NREL/TP-6A20-73067.

Madaeni, Seyed Hossein, Ramteen Sioshansi, and Paul Denholm. (2013). "Comparing Capacity Value Estimation Techniques for Photovoltaic Solar Power." IEEE Journal of Photovoltaics 3(1): 407-415. https://doi.org/10.1109/JPHOTOV.2012.2217114.

Mai, Trieu, Page Jadun, Jeffrey Logan, Colin McMillan, Matteo Muratori, Daniel Steinberg, Laura Vimmerstedt et al. (2018). Electrification Futures Study: Scenarios of Electric Technology Adoption and Power Consumption for the United States. Golden, CO: National Renewable Energy Laboratory. NREL/TP-6A20-71500. https://doi.org/10.2172/1459351. 
Maloney, Peter. (2018). "As Grid Operators File FERC Order 841 Plans, Storage Floodgates Open Slowly." Utility Dive. https://www.utilitydive.com/news/as-grid-operators-file-ferc-order$\underline{841 \text {-plans-storage-floodgates-open-slowly/543977/. }}$

Mills, Andrew, Ryan Wiser, and Joachim Seel. (2017). Power Plant Retirements: Trends and Possible Drivers. https://doi.org/10.2172/1411667.

NERC (North American Electric Reliability Corporation). (2018). Long-Term Reliability Assessment. December 2018. https://www.nerc.com/pa/RAPA/ra/Reliability\%20Assessments\%20DL/NERC_LTRA_2018 12 202018.pdf.

NREL (National Renewable Energy Laboratory). (2018). “Annual Technology Baseline and Standard Scenarios.” https://www.nrel.gov/analysis/data-tech-baseline.html.

NYISO (New York Independent System Operator.). (2017). The State of Storage: Energy Storage Resources in New York's Wholesale Electricity Markets. https://www.nyiso.com/documents/20142/2225293/2017-State-Of-Storage-Report.pdf/c80da6ffb239-3464-3b6d-f191bf62c597.

Perez, Richard, Mike Taylor, Tom Hoff, and J. P. Ross. (2008). "Reaching Consensus in the Definition of Photovoltaics Capacity Credit in the USA: A Practical Application of SatelliteDerived Solar Resource Data." IEEE Journal of Selected Topics in Applied Earth Observations and Remote Sensing 1(1): 28-33. http://dx.doi.org/10.1109/JSTARS.2008.2004362.

PGE (Portland General Electric). (2016). Integrated Resource Plan. https://www.portlandgeneral.com/-/media/public/our-company/energy-strategy/documents/2016irp.pdf.

Salles, Mauricio B. C., Junling Huang, Michael J. Aziz, and William W. Hogan. (2017). "Potential Arbitrage Revenue of Energy Storage Systems in PJM." Energies 0(8): 1996-1073. https://doi.org/10.3390/en10081100.

Schmidt, Oliver, Sylvain Melchior, Adam Hawkes, and Iain Staffell. (2019). "Projecting the Future Levelized Cost of Electricity Storage Technologies." Joule (3)1: 81-100. https://doi.org/10.1016/i.joule.2018.12.008.

Sengupta, Manajit, Andrew Weekley, Aron Habte, Anthony Lopez, and Christine Molling. (2015). Validation of the National Solar Radiation Database (NSRDB) (2005-2012). Golden, CO: National Renewable Energy Laboratory. NREL/CP-5D00-64981.

Shi, Nian, and Yi Luo. (2017). "Capacity Value of Energy Storage Considering Control Strategies.” PLoS ONE 12(5), e0178466. https://doi.org/10.1371/journal.pone.0178466.

Sioshansi, Ramteen, Seyed Hossein Madaeni, and Paul Denholm. (2014). "A Dynamic Programming Approach to Estimate the Capacity Value of Energy Storage." IEEE Transactions on Power Systems 29(1): 395-403. http://dx.doi.org/10.1109/TPWRS.2013.2279839. 
Strategen Consulting. (2017). New York City's Aging Power Plants: Risks, Replacement Options, and the Role of Energy Storage. Berkeley, CA: Strategen Consulting. https://www.strategen.com/s/Strategen-NYC-Power-Plants-and-Energy-Storage-92020173mgr.pdf.

Wadia, Cyrus, Paul Albertus, and Venkat Srinivasan. (2011). "Resource Constraints on the Battery Energy Storage Potential for Grid and Transportation Applications." Journal of Power Sources 196(3): 1593-1598. https://doi.org/10.1016/j.jpowsour.2010.08.056.

Zhang, Xinmin, Yuan Li, Siyuan Lu, Hendrik F. Hamann, Bri-Mathias Hodge, and Brad Lehman. (2019). "A Solar Time Based Analog Ensemble Method for Regional Solar Power Forecasting." IEEE Transactions on Sustainable Energy 10(1): 268-279. https://doi.org/10.1109/TSTE.2018.2832634. 


\section{Appendix}

\section{Practical Potentials for 4-Hour Storage in All 18 Regions as a Function of PV Penetration}
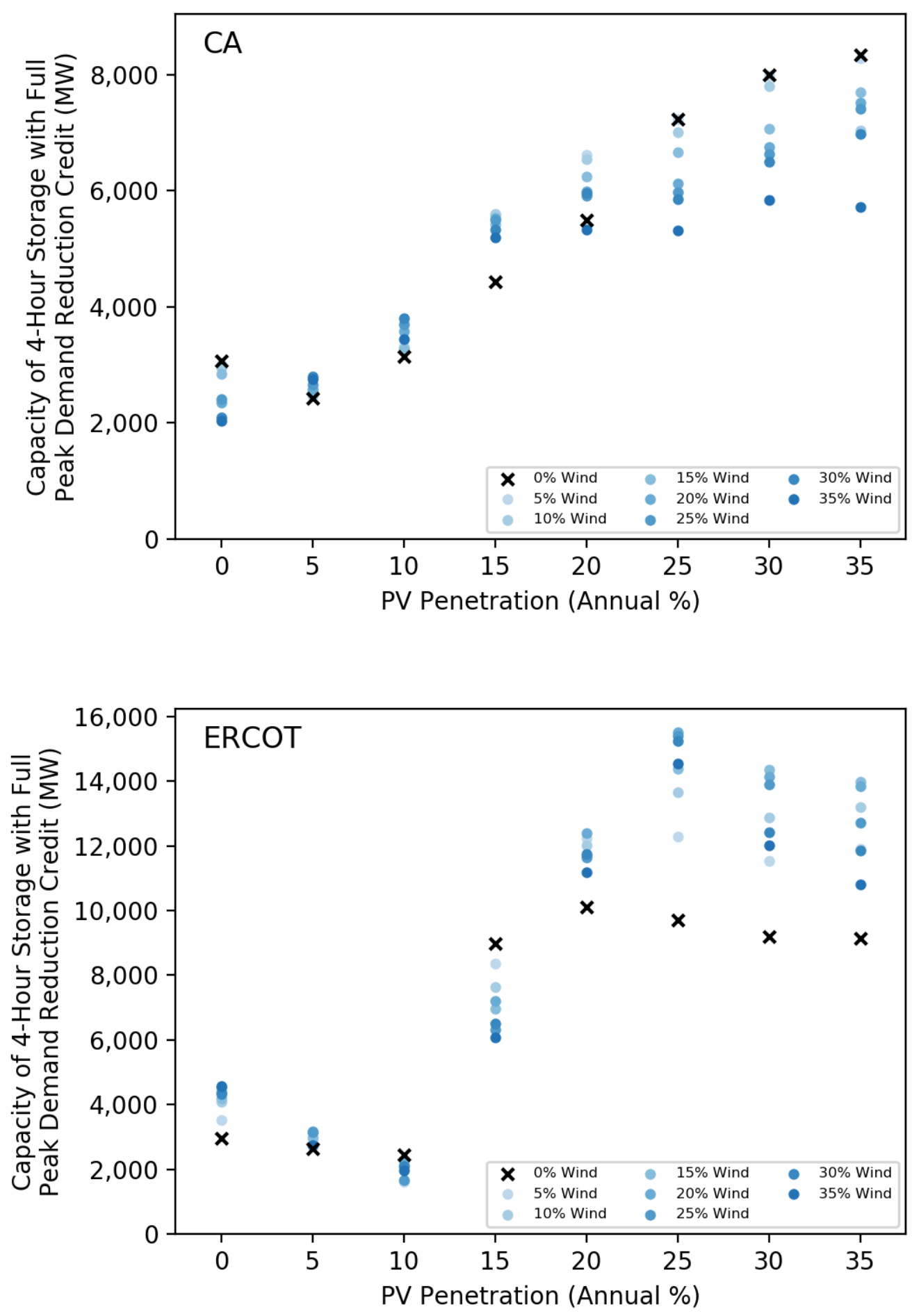

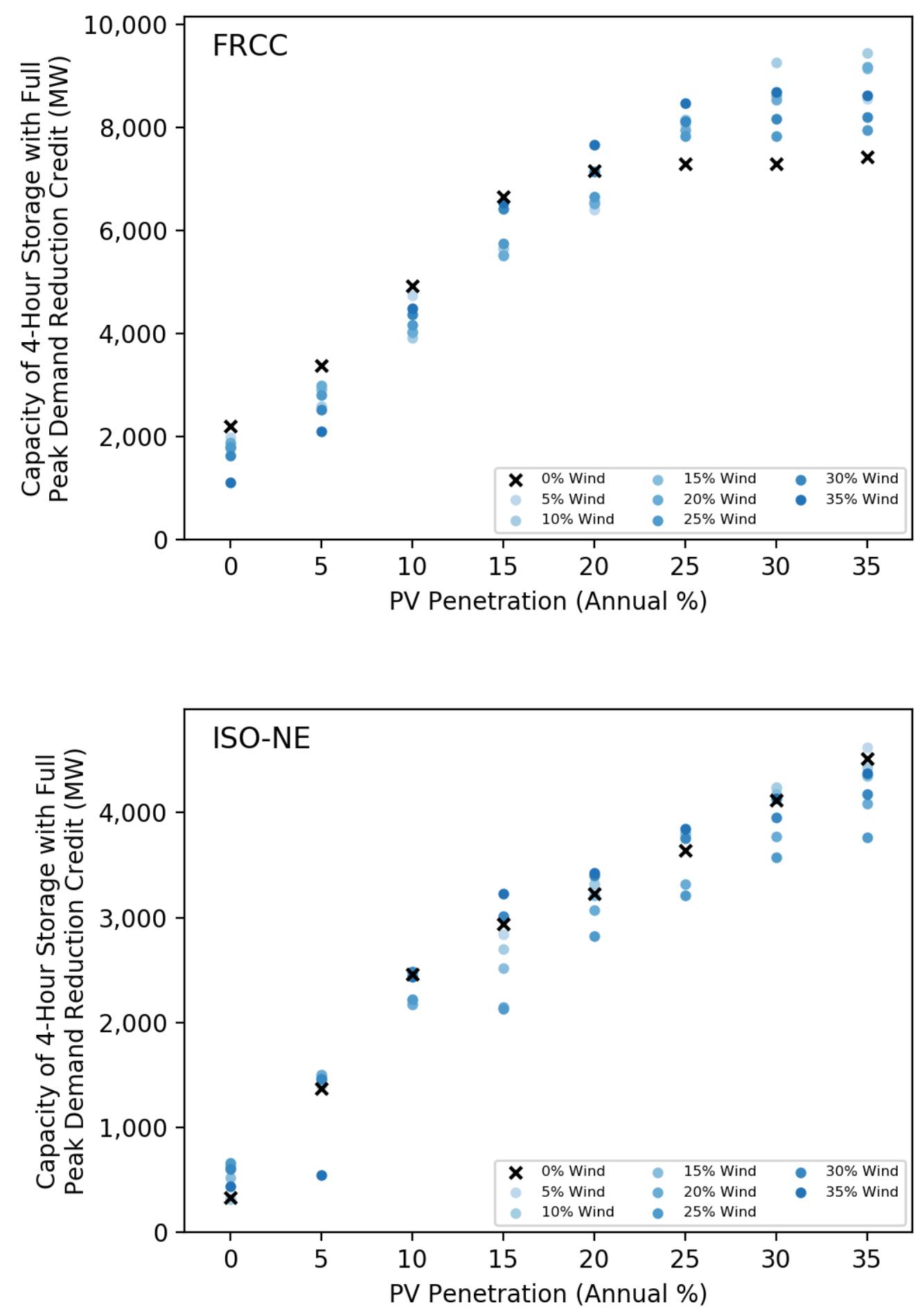

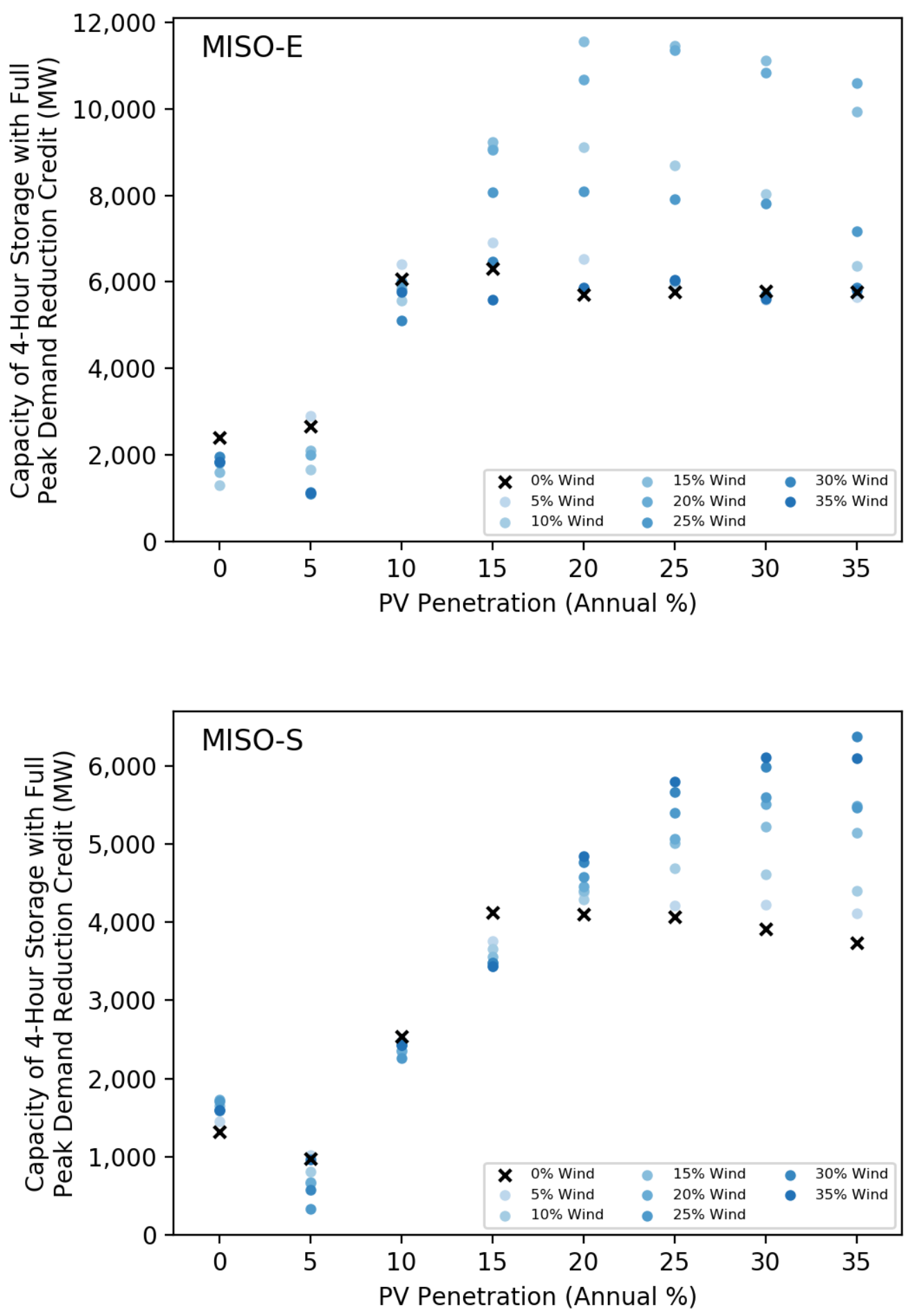

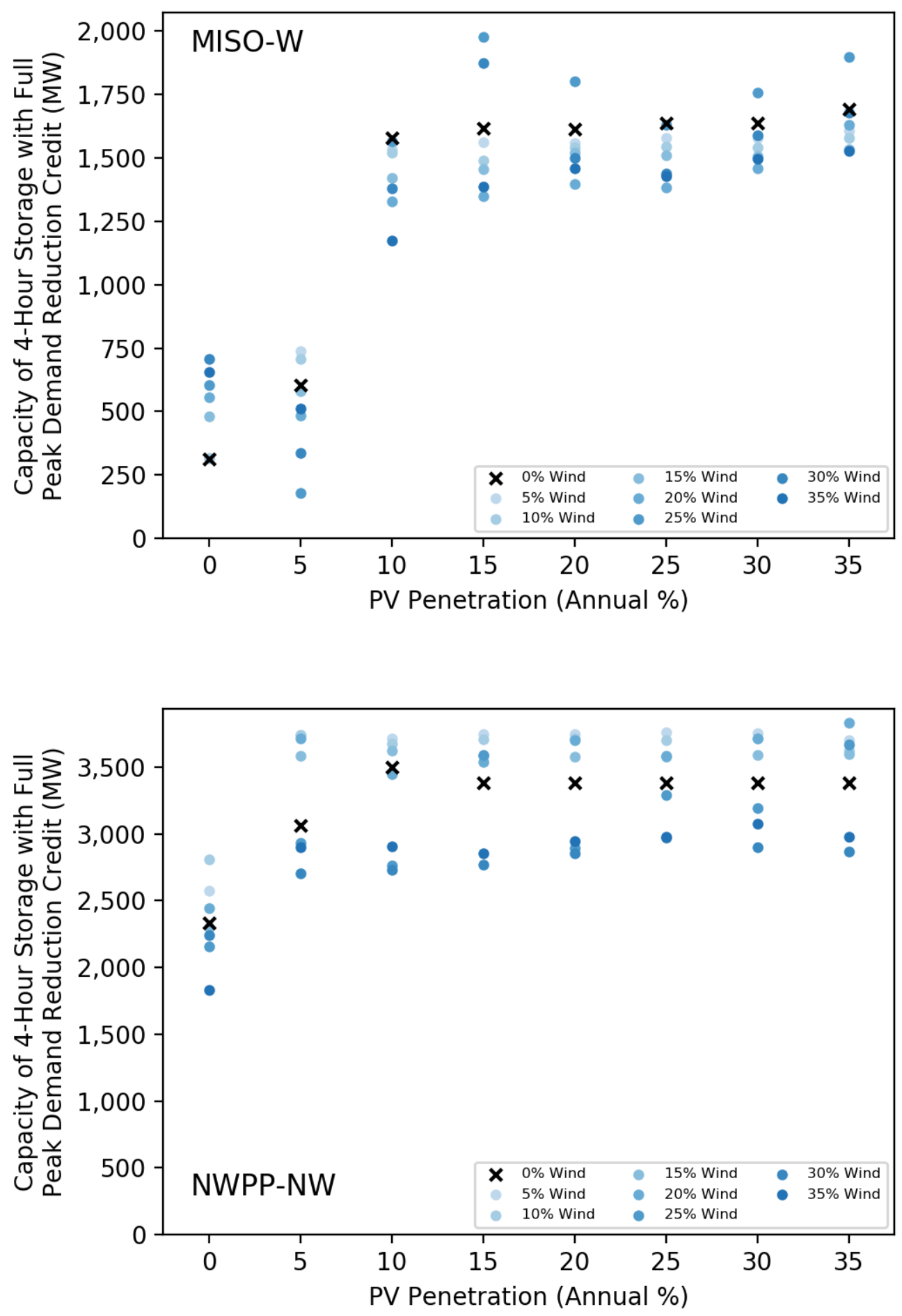

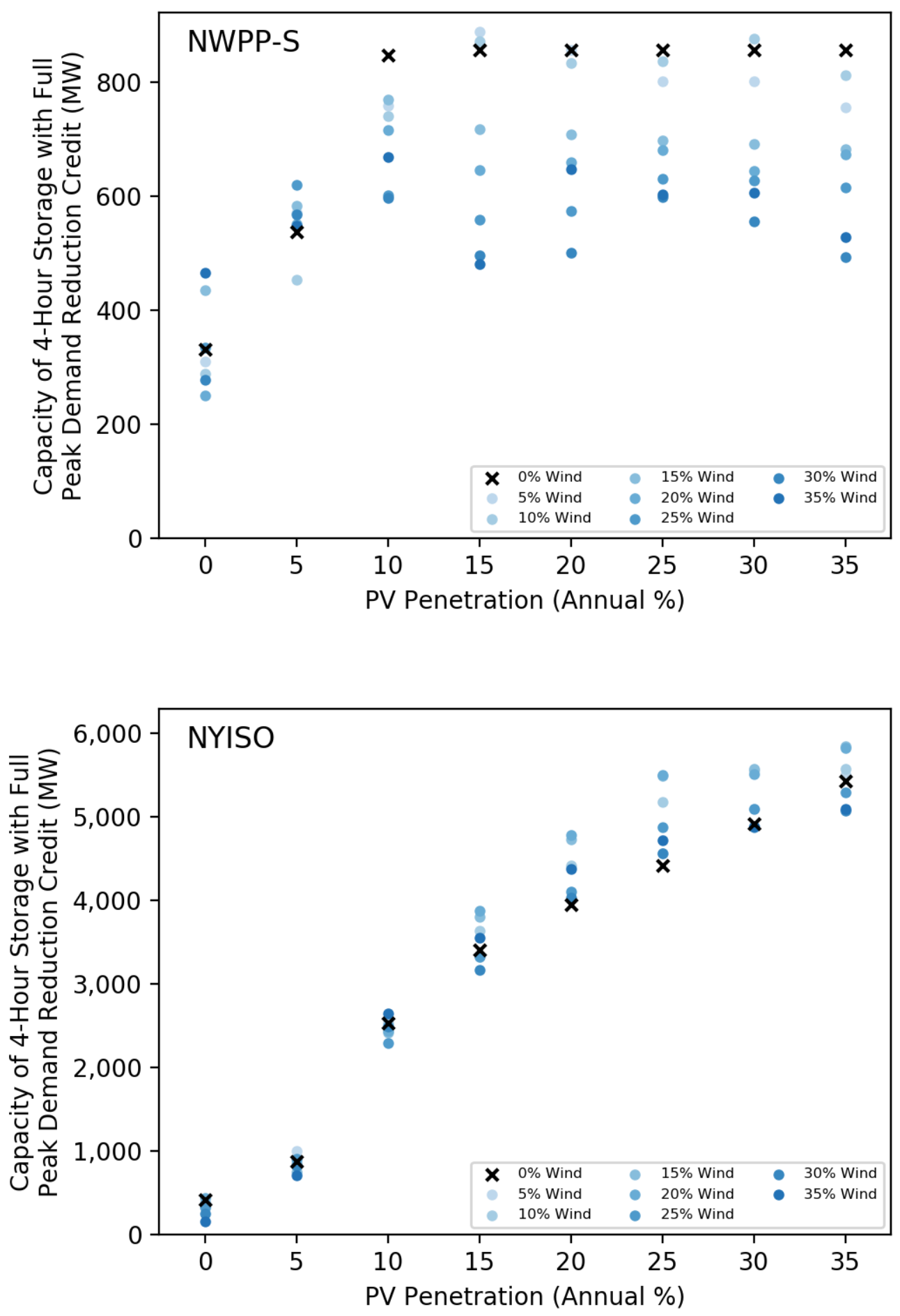

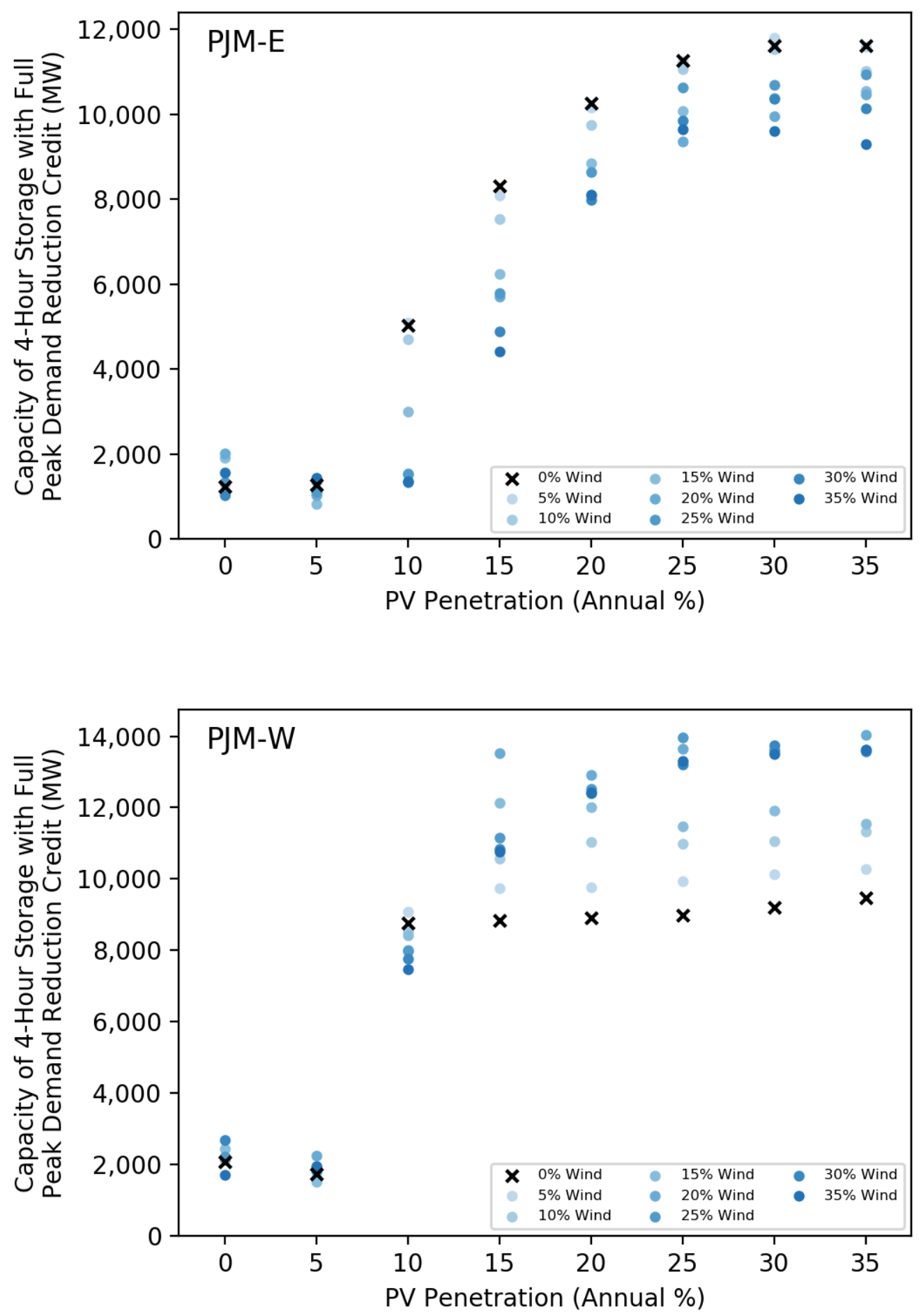

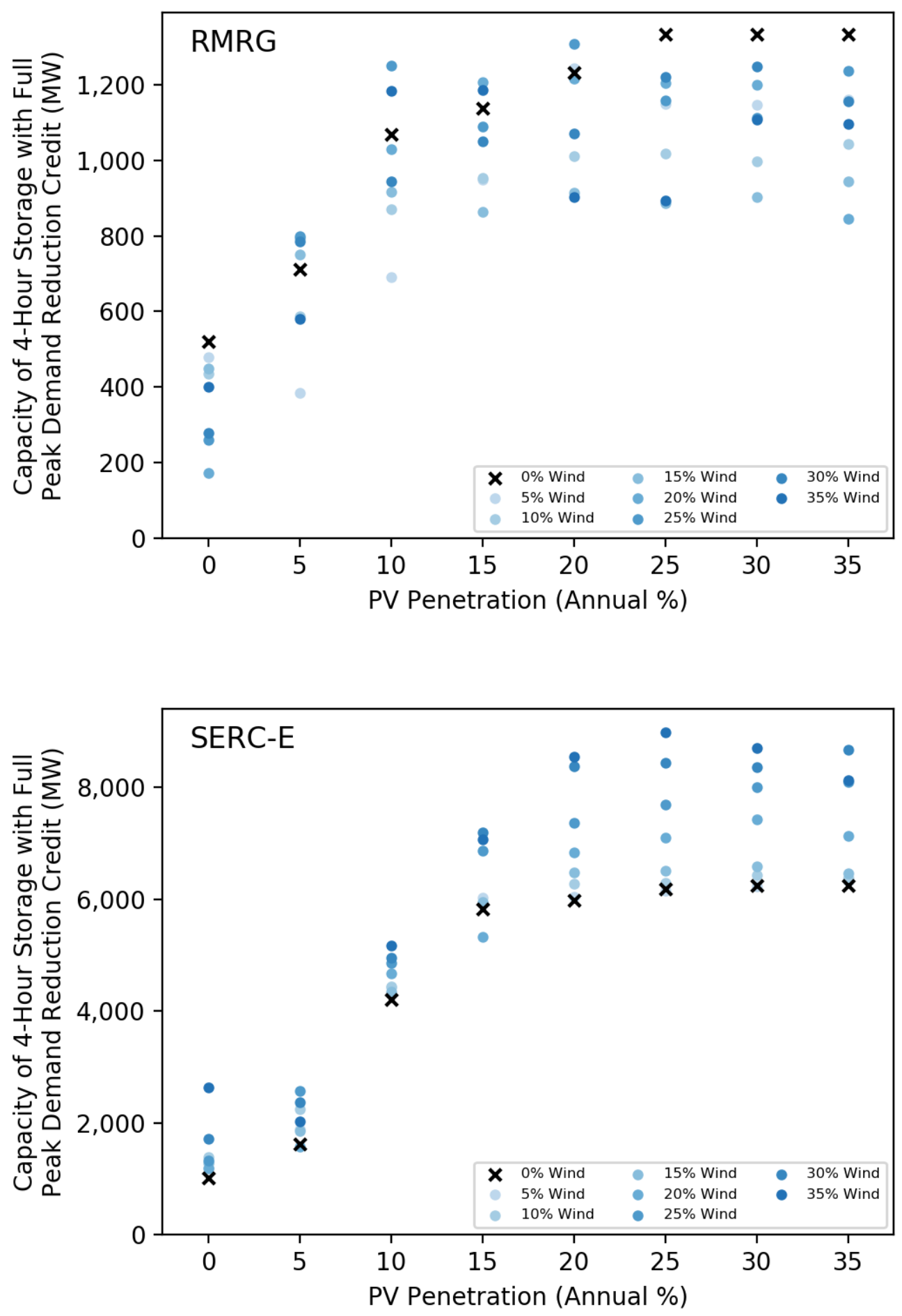

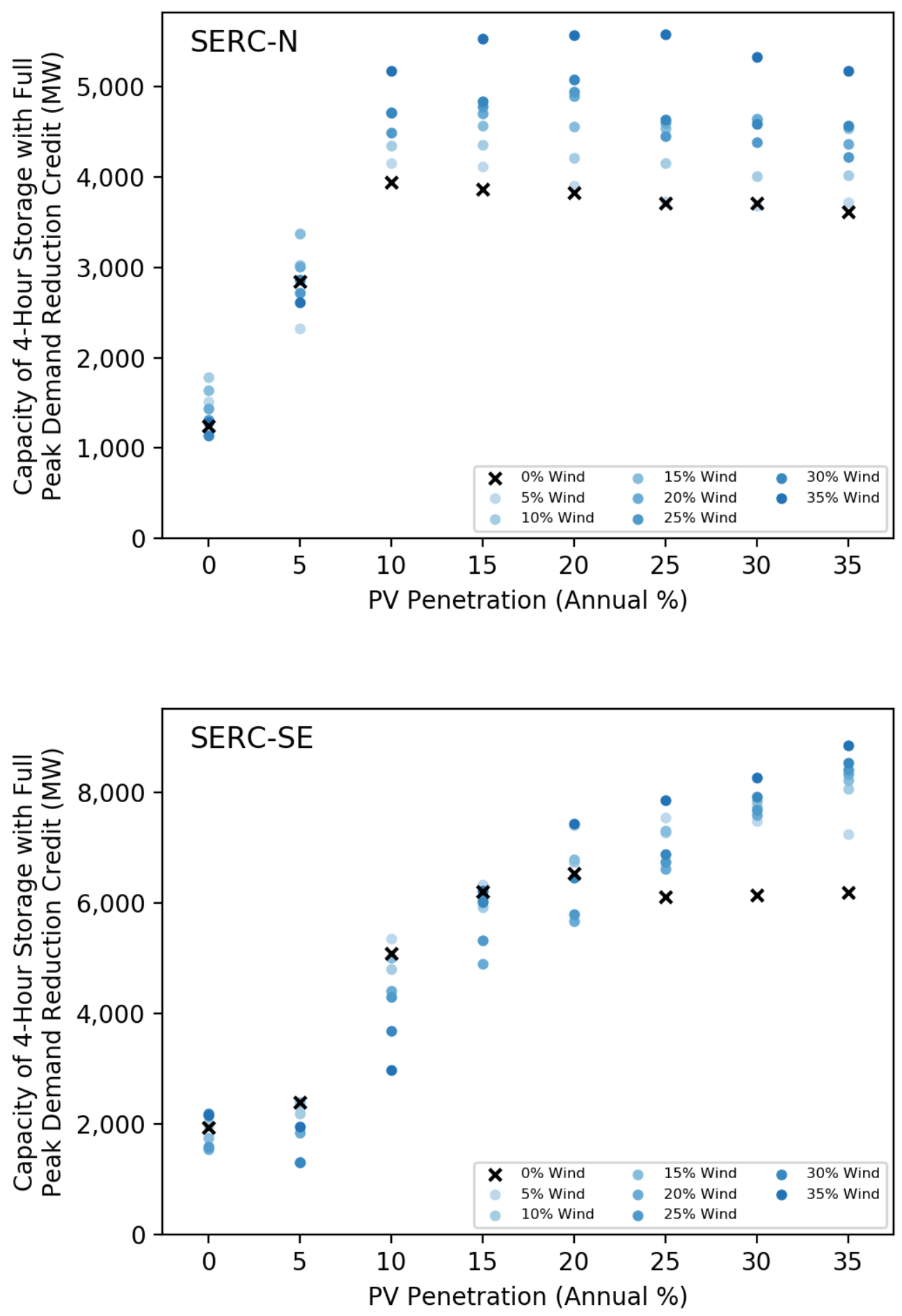

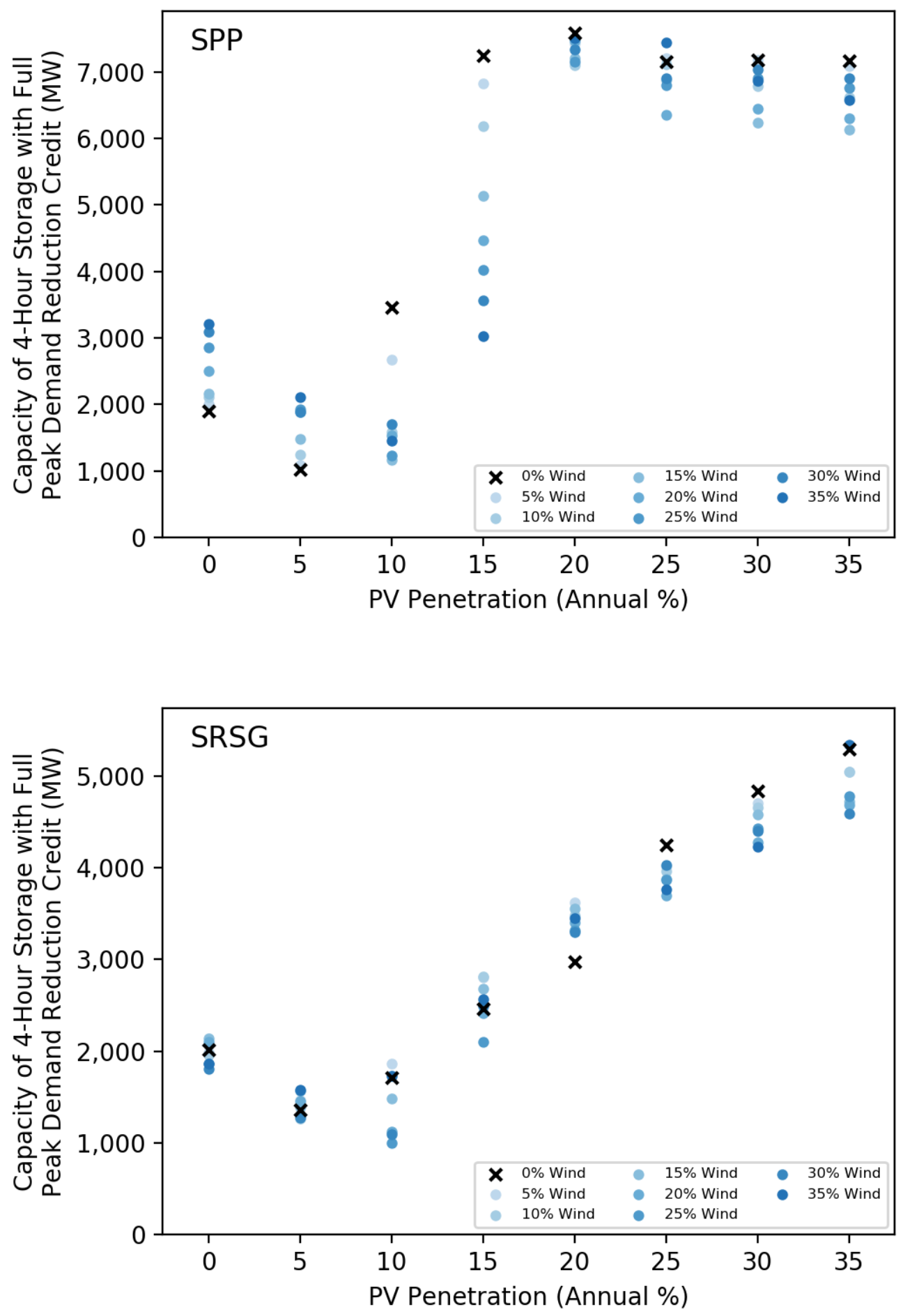
Practical Potentials for 4-Hour Storage in All 18 Regions as a Function of Wind Penetration
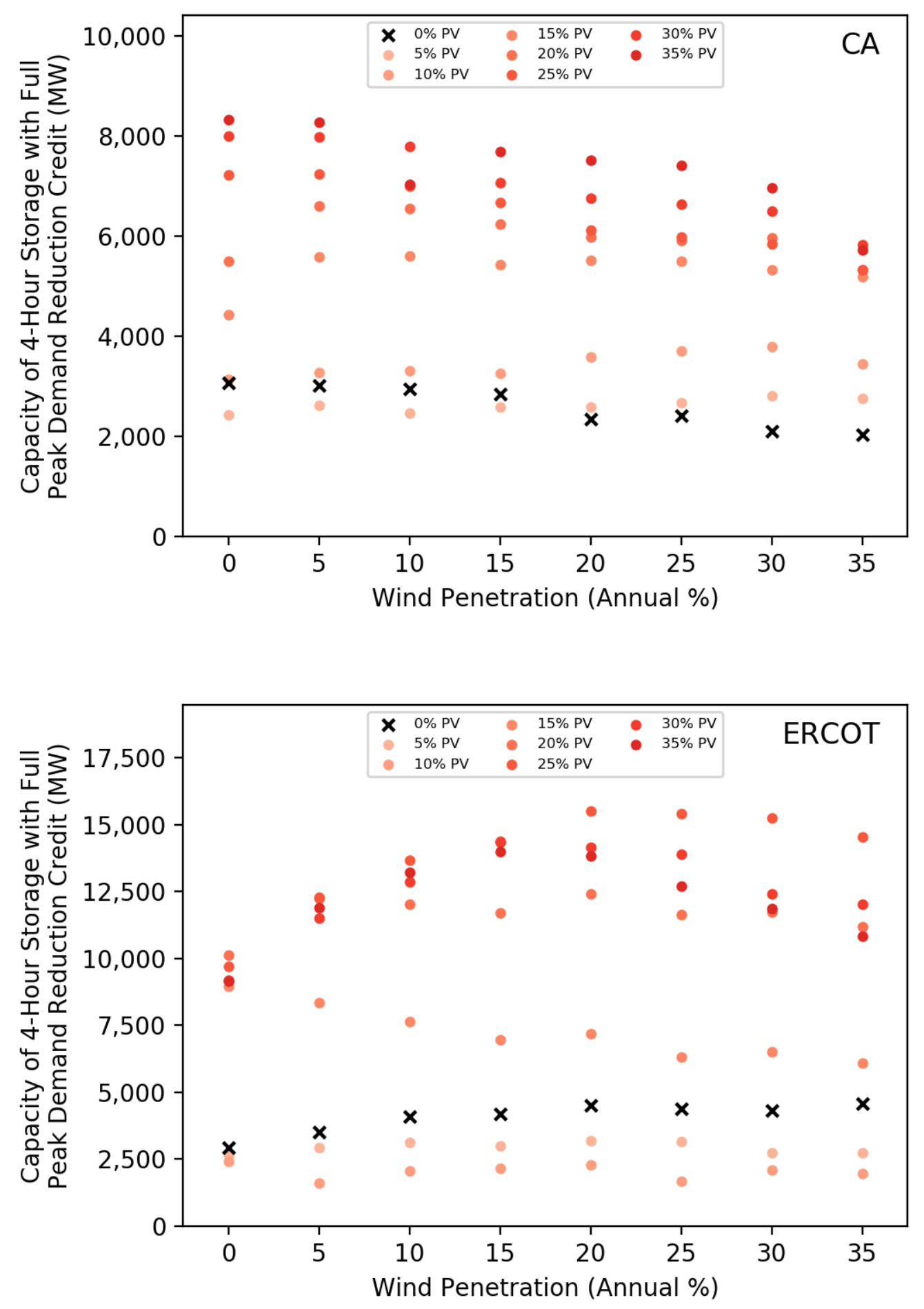

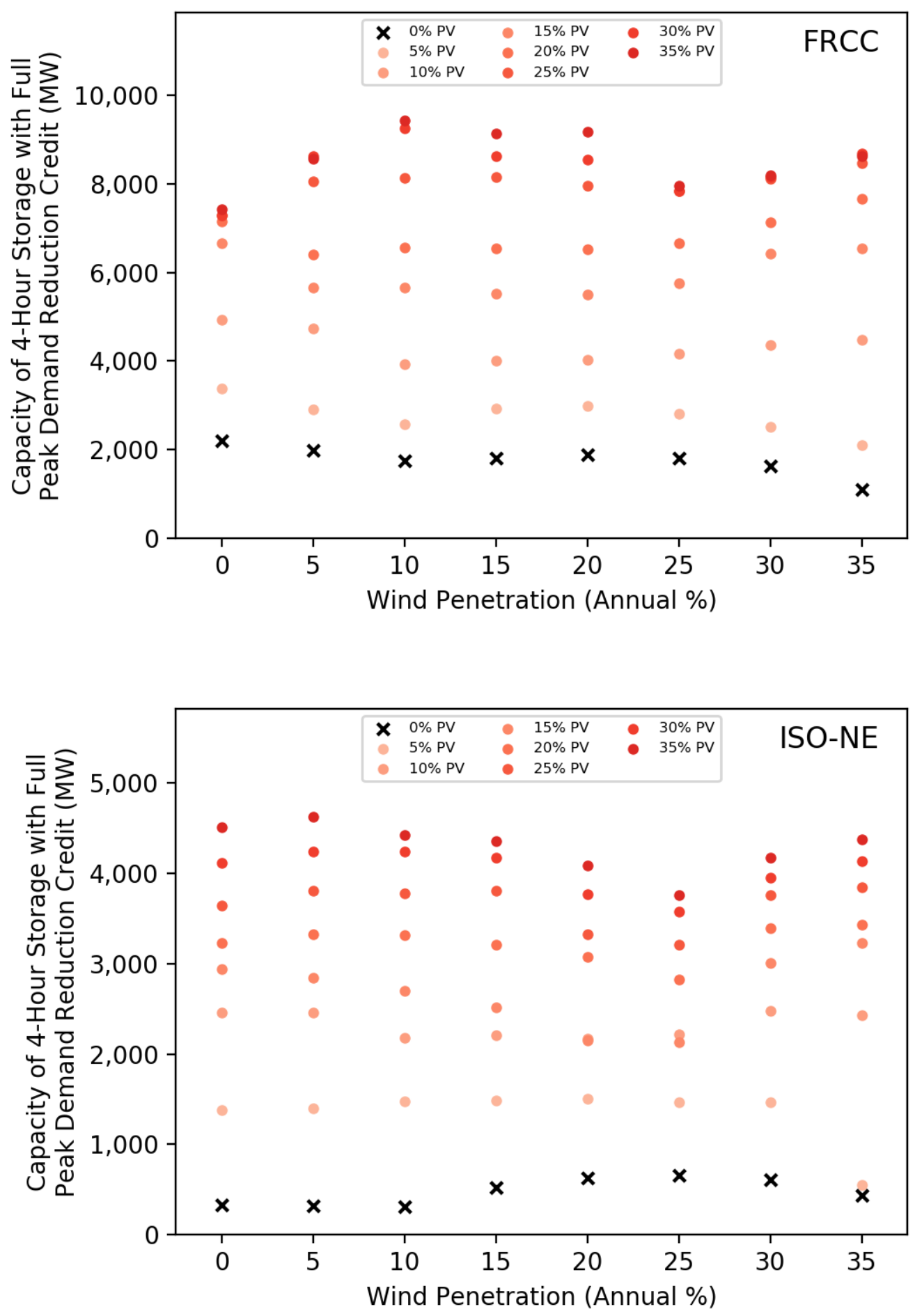

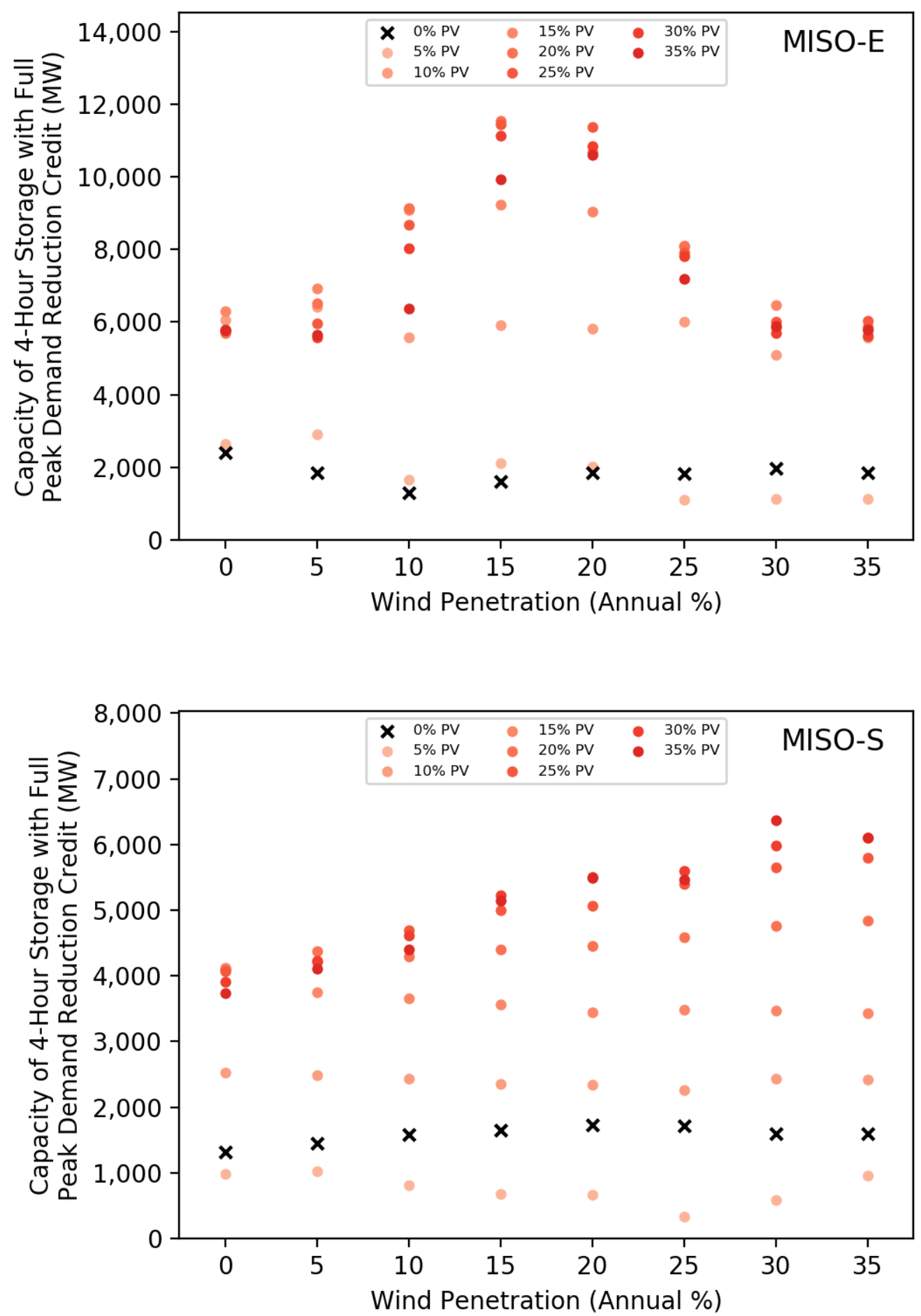

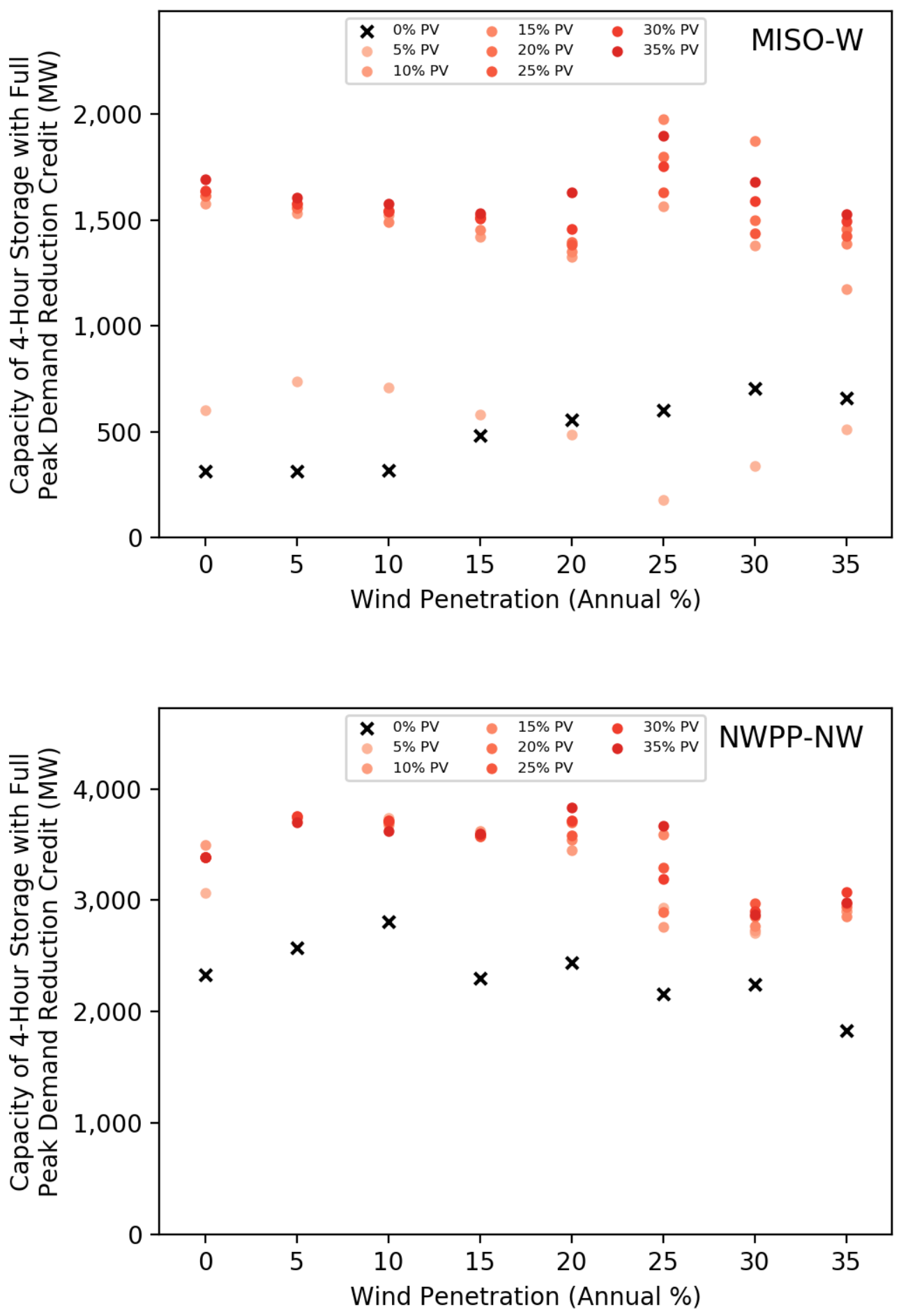

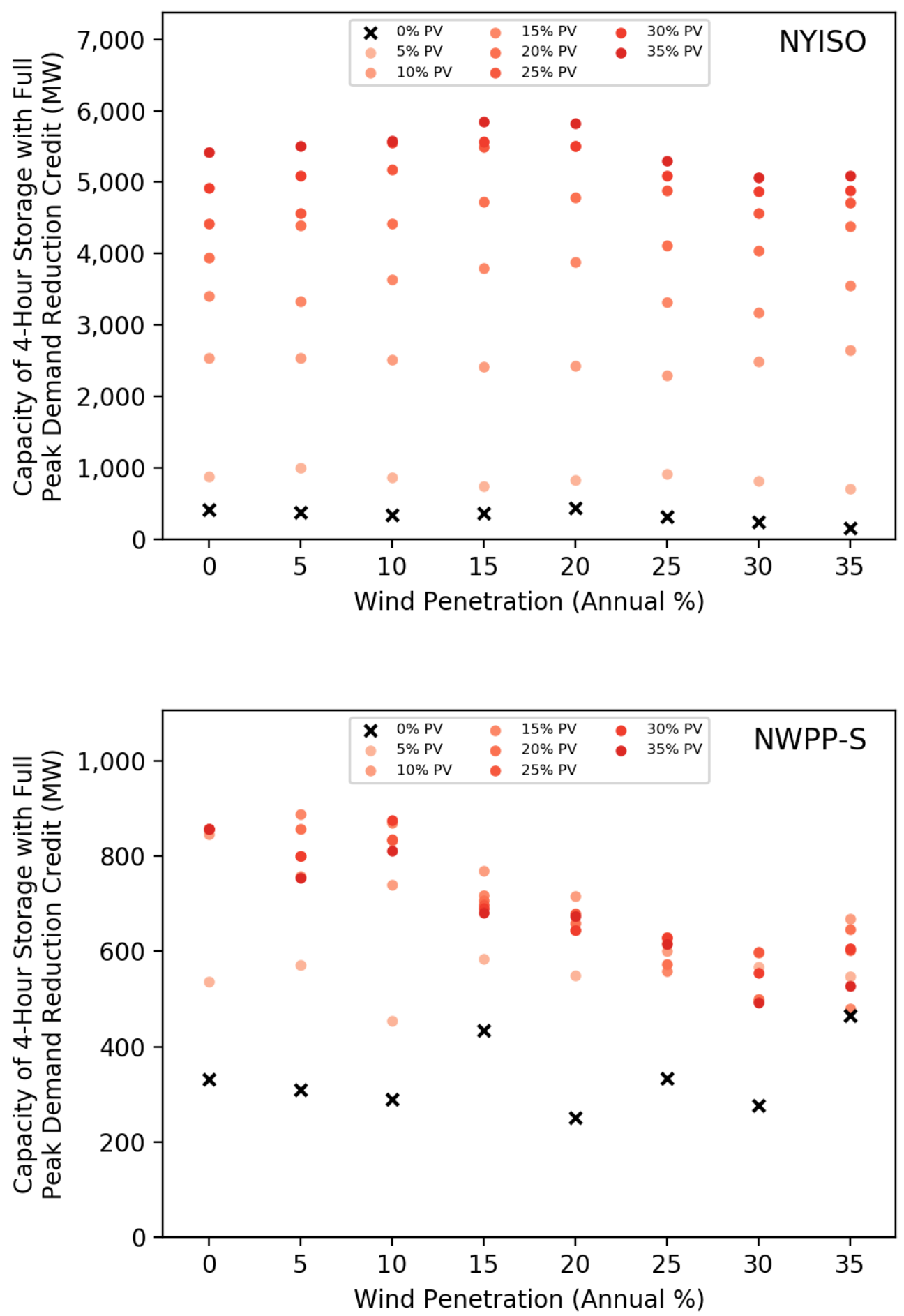

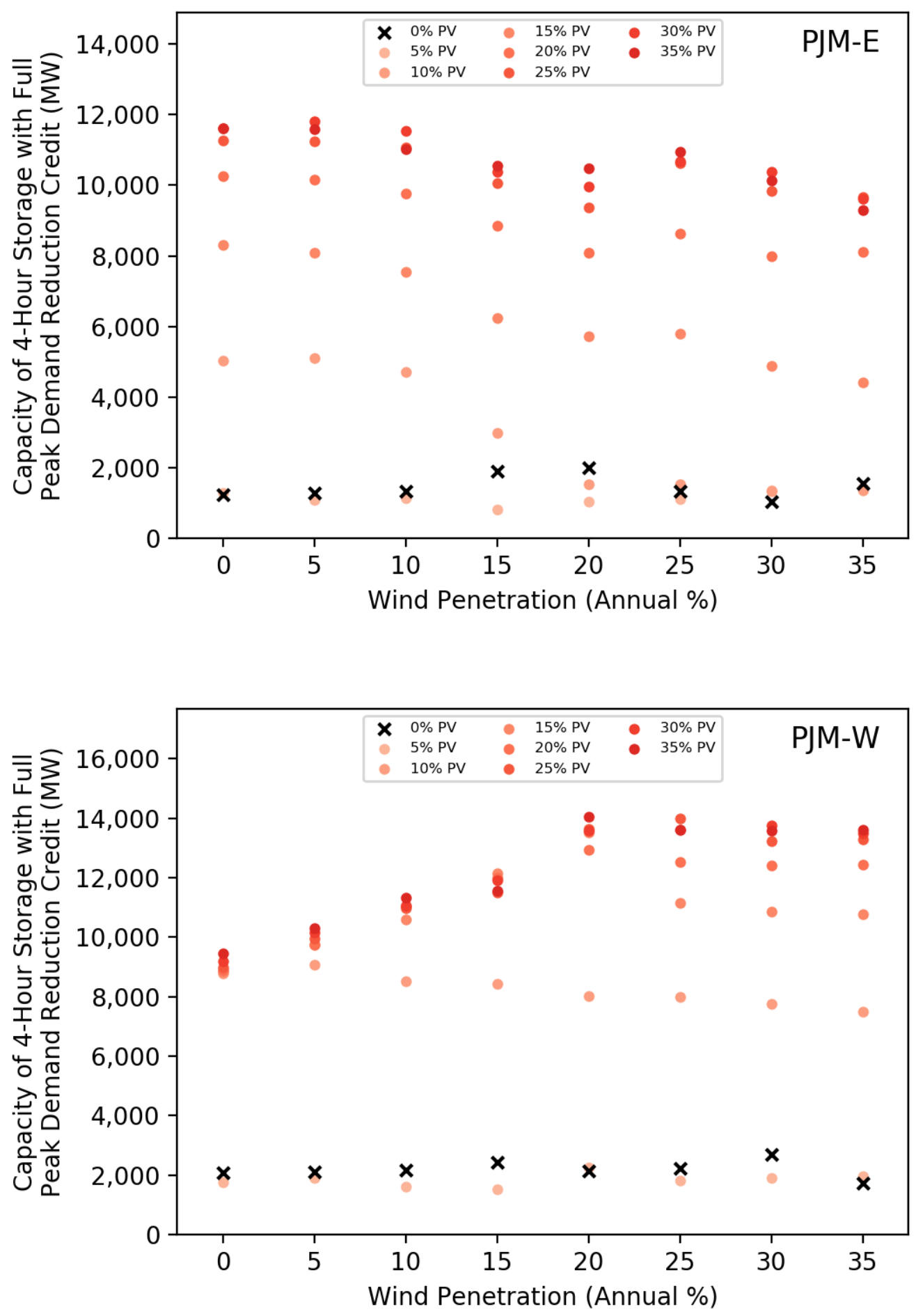

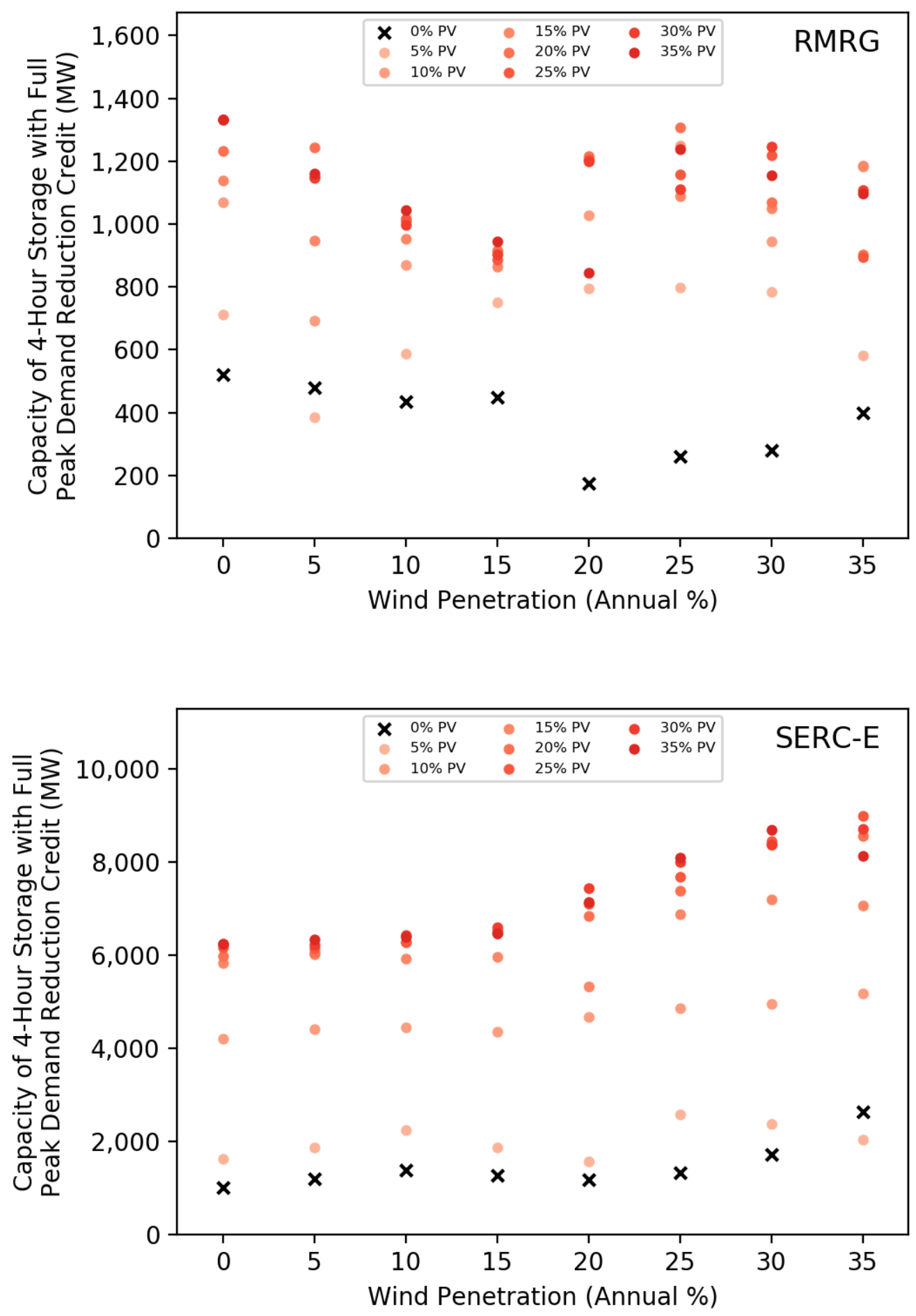

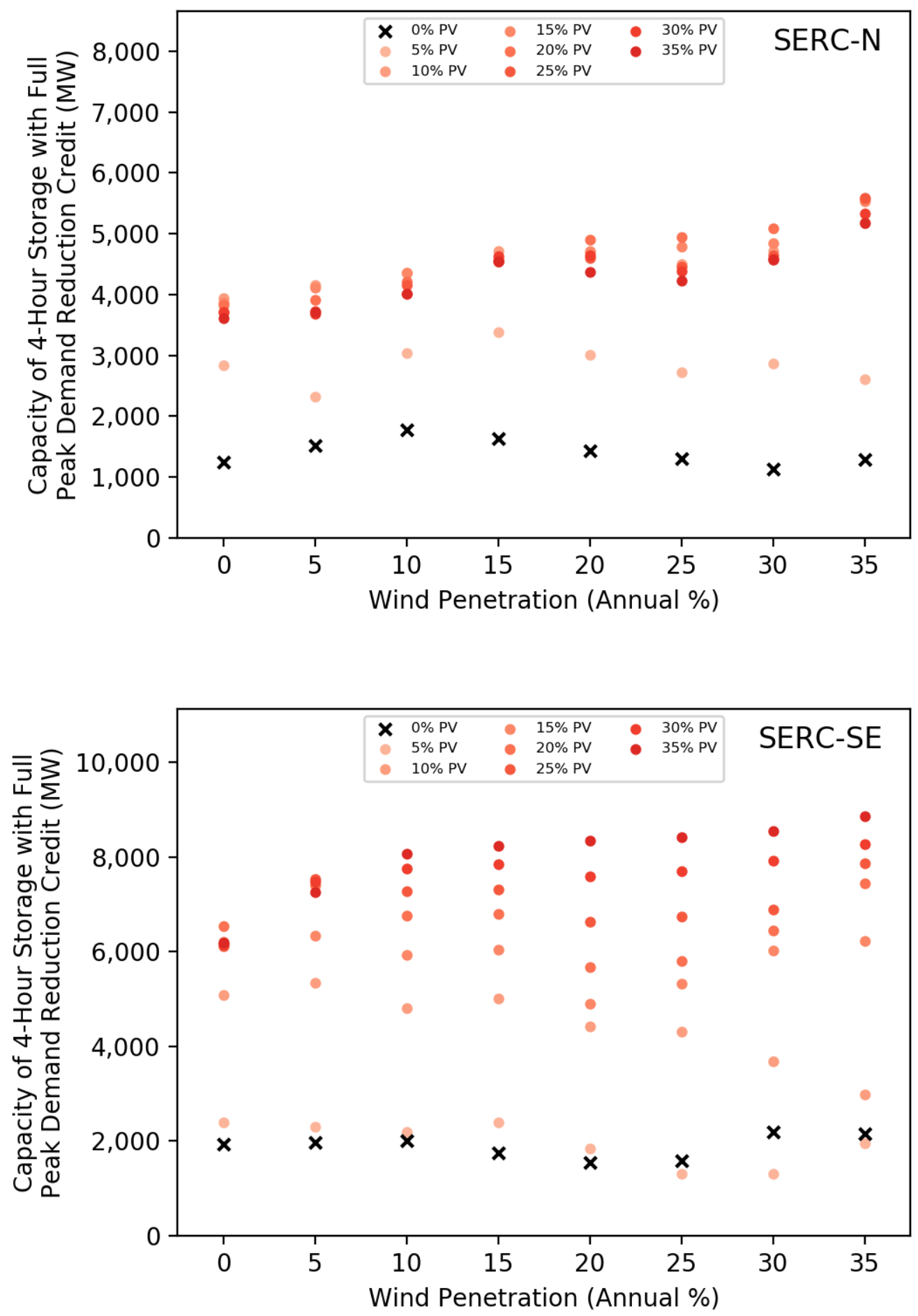

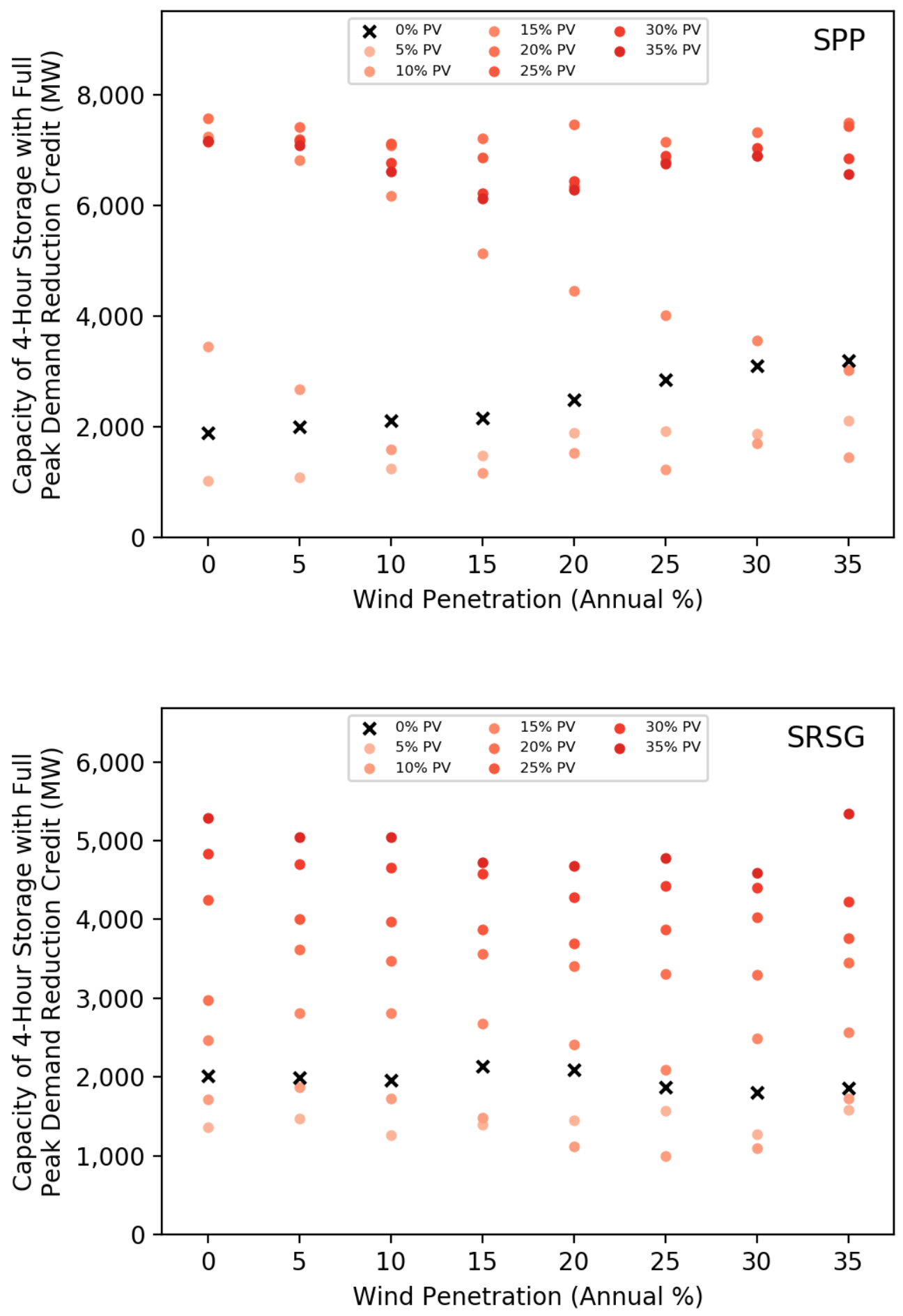


\section{National Practical Potentials for 4-Hour, 6-Hour, and 8-Hour Storage as a Function of Wind Penetration}

The figure below plots the overall national practical potential for 4-hour energy storage for about 20,000 combinations of VG penetration. It uses the same data as in Figure 4 in the main text, but just using the 4-hour data, and plotted as a function of wind penetration, instead of PV. Each of the five lines represents a cluster of PV penetration levels, indicated by the legend to the right of the figure. The trend lines were obtained using a Savgol filter with a window of 1,001 observations and convolution coefficient of 3 . There are no clear trends, which reinforces the finding that increases in the potential for storage will be driven more by PV than by wind.

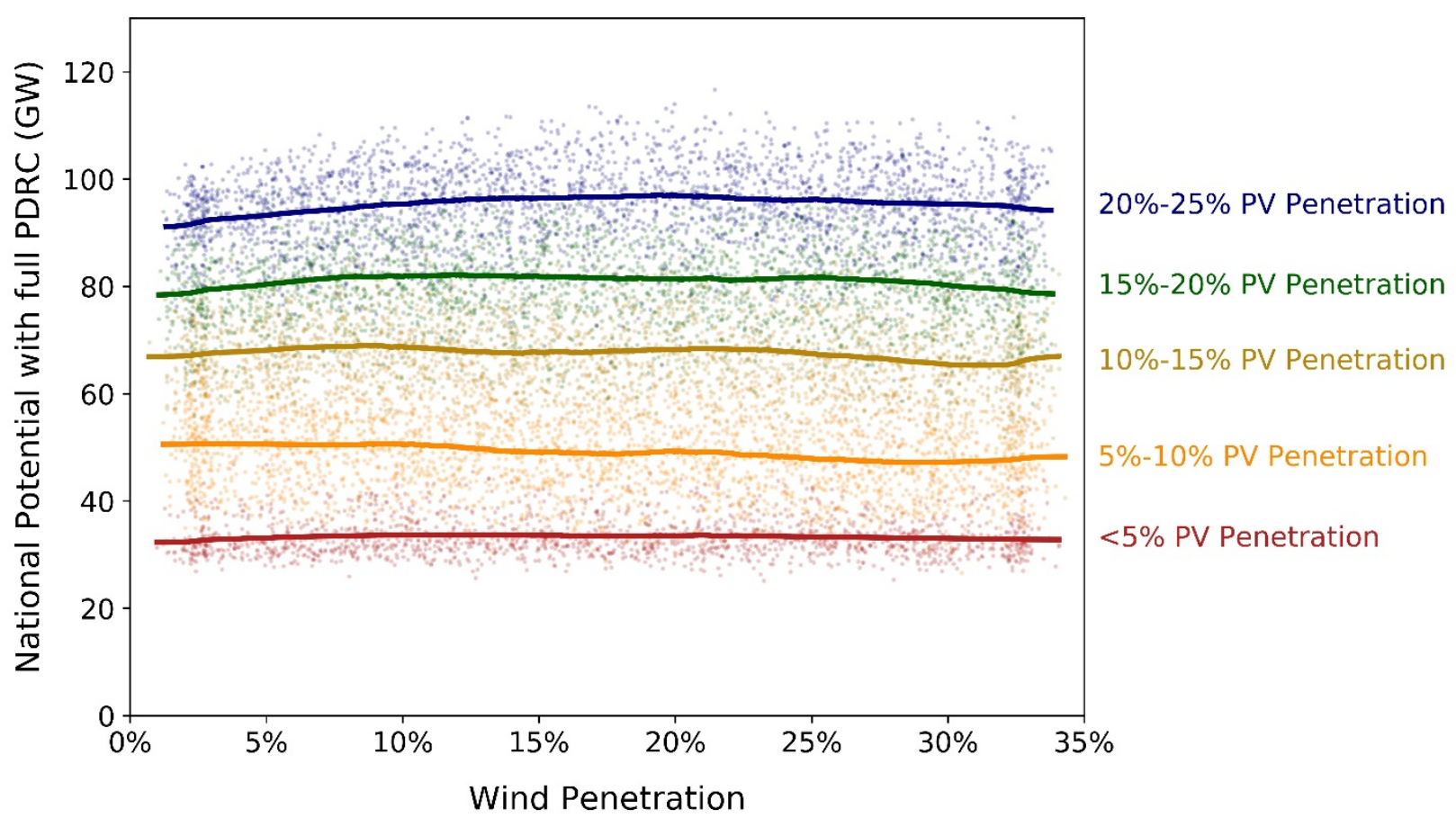

